\title{
The Impact of Local Meteorological Conditions on Airframe Noise Flight Test Data
}

\author{
David P. Lockard* \\ NASA Langley Research Center, Hampton, VA 23681 \\ Kimberly A. Bestul ${ }^{\dagger}$ \\ Jacobs Technology, Inc. Edwards, CA 93523
}

\begin{abstract}
Phased microphone array measurements obtained during flight tests conducted in 2016 and 2017 are used to assess the importance of local meteorological measurements on the data. In particular, the effectiveness of atmospheric absorption corrections is evaluated under vastly different temperature and humidity conditions. The results indicate that, even under conditions with high absorption, sources can be visualized up to a frequency that is dependent on background noise levels, wind, and atmospheric turbulence. However, absolute levels were found to be problematic on days with high absorption rates, with the discrepancies most prevalent for aircraft positions further from the center of the array. Restricting the data to those days with favorable meteorological conditions generally resulted in a good collapse of the spectra, with differences less than a couple of decibels.
\end{abstract}

\section{Introduction}

A $250 \mathrm{ft}(76 \mathrm{~m})$ diameter microphone array[1, 2] developed for airframe noise flyover measurements is being used to perform acoustic measurements of a Grumman Gulfstream ${ }^{\circledR}$ III aircraft at the NASA Armstrong Flight Research Center (AFRC). The array consists of 185 microphones on ground plates along with the associated data acquisition hardware. Acquisition control and signal processing, including array beamforming[3], is performed with the AVEC Time Domain Beamforming Code[4]. A view of the command trailer with the array in the background is shown in Fig. 11.a) and an aerial view of the array is shown in Fig. 1 (b).

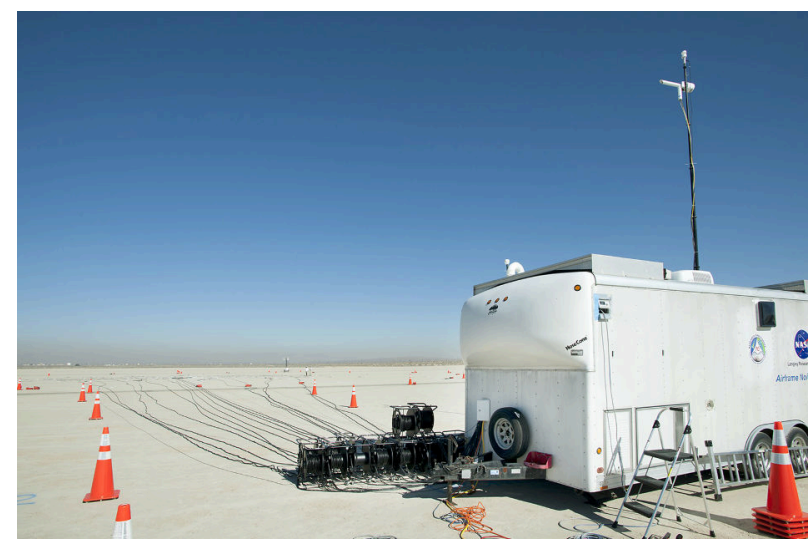

(a) Ground

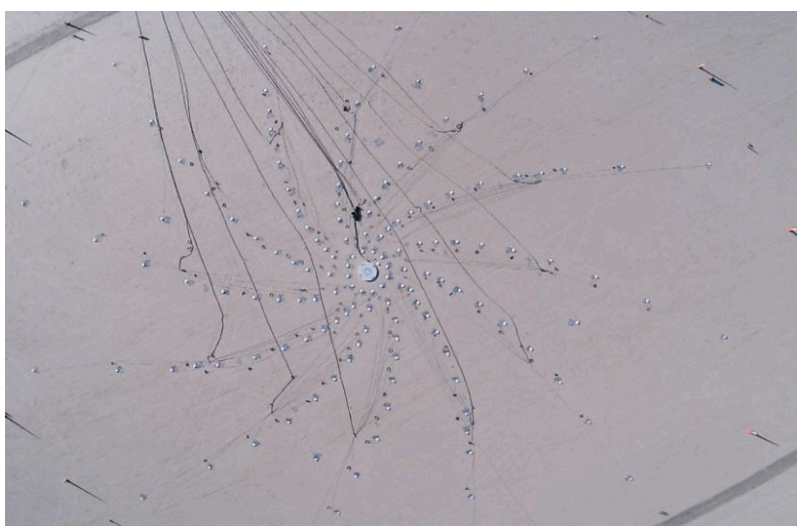

(b) Aerial

Fig. 1 Views of the Microphone Array

Flight tests occurred between September - October, 2016 and August - October, 2017. The goal of the testing is to demonstrate the potential of devices to reduce airframe noise. In particular, flap side-edge and landing gear noise is targeted during this test campaign[5]. Acoustic flight test data is dependent on several aircraft factors including the following: ground and air speed, position relative to microphones, attitude (including the angle of attack, roll, pitch, and yaw), and engine settings. However, the local meteorological conditions are equally important, which include the temperature, relative humidity, pressure, and wind. Appendix A of the Code of Federal Regulations Title 14, Chapter I, Subchapter C, Part 36 defines strict guidelines for the required atmospheric observations for noise certification measurements. However,

\footnotetext{
*Aerospace Technologist, Computational AeroSciences Branch, Mail Stop 128, Senior Member, AIAA

${ }^{\dagger}$ Meteorologist, NASA Armstrong Flight Research Center, PO Box 273
} 
these regulations were developed for industrial use and not for a research environment. The standard was defined for $1 / 3$ octave band measurements with pole mounted microphones, not the narrow band spectra from many ground mounted microphones typical of phased array research. Furthermore, NASA AFRC is located in the Mojave desert of California, and the atmospheric conditions can vary dramatically from day to day and from hour to hour. Variability in some of these conditions can require special treatment. In particular, surface temperature inversions (where the temperature increases with altitude) are very common, and the standard calls for atmospheric corrections for absorption to be calculated in layers [6] rather than using a single average for the temperature and relative humidity over the entire distance of propagation.

For the flight test campaigns at NASA AFRC, the atmospheric restriction recommendations of McCollough and True[7] were adapted for airframe noise measurements using a microphone array. Sound attenuation was calculated using the formula developed by Bass et al.[8-10], which forms the basis of the standards ISO 9613-1, "Acoustics - Attenuation of sound during propagation outdoors - Part 1:Calculation of the absorption of sound by the atmosphere," and ANSI S1.26-1995, "Method for Calculation of the Absorption of Sound by the Atmosphere." The formula predicts the pure-tone (or narrow band) atmospheric attenuation that has been used to derive the 1/3 octave tables in the standards defined in SAE ARP866A and SAE ARP5534. The attenuation over $328 \mathrm{ft}(100 \mathrm{~m})$ as a function of temperature and relative humidity is shown in Fig. 2 for frequencies between 1 and $6 \mathrm{kHz}$. The black line superimposed on the contours shows the desired temperature and relative humidity window recommended in Ref. [7]. Although the attenuation is a function of the pressure, the dependence is relatively weak. The contours were calculated for the pressure at $2200 \mathrm{ft}(680 \mathrm{~m})$, which is the altitude of NASA AFRC. The contours demonstrate that the attenuation increases strongly with frequency and is higher for colder, drier air. The recommended testing window does not include temperatures over $95^{\circ} \mathrm{F}\left(35^{\circ} \mathrm{C}\right)$ nor relative humidities over $95 \%$ because of practical considerations related to equipment functionality. The lower line follows a curve of constant attenuation and limits the correction to less than $10 \mathrm{~dB}$ at $6 \mathrm{kHz}$. The white contours in the figures are saturated, and the maximum attenuation in Fig. 2(f) is over $20 \mathrm{~dB}$.

Acoustic measurements are often reported at the conditions of the standard acoustic day[11]: relative humidity of 70\%, temperature of $77^{\circ} \mathrm{F}\left(25^{\circ} \mathrm{C}\right)$, and pressure of $2116 \mathrm{psf}(101.3 \mathrm{kPa})$. The attenuation at $6 \mathrm{kHz}$ is limited to $4 \mathrm{~dB}$ for the standard acoustic day, but such favorable conditions can be difficult to obtain. Instead, one must rely on the attenuation formula to correct the data. The recommended limits on the temperature and humidity keep the corrections within a range deemed reasonable, but also play a role on the validity of the data at high frequency because of background noise. In addition to the ambient noise at the test site, all data acquisition systems possess an electronic background noise, which tends to dominate at higher frequencies. Furthermore, self-noise can be problematic on windy days, affecting a wide range of frequencies. When the noise from the aircraft is attenuated to within approximately $3 \mathrm{~dB}$ of the background levels for the system, single microphone measurements can not be trusted. Hence, the FAA standard requires that the collected data be replaced by extrapolated values. The frequency at which this occurs is dependent on the local atmospheric conditions and the data acquisition system. A microphone array can isolate the noise from an aircraft even when the noise from the plane is below the background[3]. However, the ability to reject extraneous noise is dependent on the number of microphones and design of the array. Furthermore, the distribution of sources is important as well as the relative intensity of the background noise to that of the aircraft. Although an array is better able to deal with background noise than a single microphone, the improvement is highly dependent on the equipment and conditions.

Other important parameters for flight test measurements include the aircraft position and the wind speed. For the current test, the nominal altitude at the center of the array was specified as $350 \mathrm{ft}(106.7 \mathrm{~m})$ with a tolerance of $\pm 50 \mathrm{ft}(15$ $\mathrm{m})$. The lateral deviation from the center of the array was limited to $\pm 30 \mathrm{ft}(7.5 \mathrm{~m})$. Aircraft position was obtained via a differential GPS system. The wind limits between the surface and $400 \mathrm{ft}(122 \mathrm{~m})$ were defined as: maximum wind speed $<13$ knots, average wind speed $<10$ knots, maximum crosswind $<9$ knots, average crosswinds $<6$ knots. The wind not only affects the aircraft and acoustic propagation but also generates self-noise on the microphones, which raises the background noise levels. Although average wind values were used in the array processing, the winds tend to vary too rapidly for its inclusion to make much difference in the processing.

\section{Instrumentation}

Atmospheric measurements near the surface were made with two instrument suites that measured the temperature, relative humidity, pressure, wind speed and wind direction. One sensor suite was mounted on a tripod extended to $10 \mathrm{ft}$ (3 m) (see Fig. 3. a)), and the other was on a $30 \mathrm{ft}(10 \mathrm{~m})$ mast on top of the command trailer (see Figs. 1 (b) and 3 .b)). While both sensor suites contain an aspirated temperature / humidity sensor and atmospheric pressure gauge, the 30ft weather station utilizes a sonic anemometer for wind speed and direction whereas the $10 \mathrm{ft}(3 \mathrm{~m})$ tower is equipped with a mechanical propeller anemometer. Time-stamped sampling of local conditions occurred on half-second intervals, with 1-minute averages used for data processing.

Vertical profiles of the atmospheric temperature, pressure, and relative humidity were obtained hourly by using 


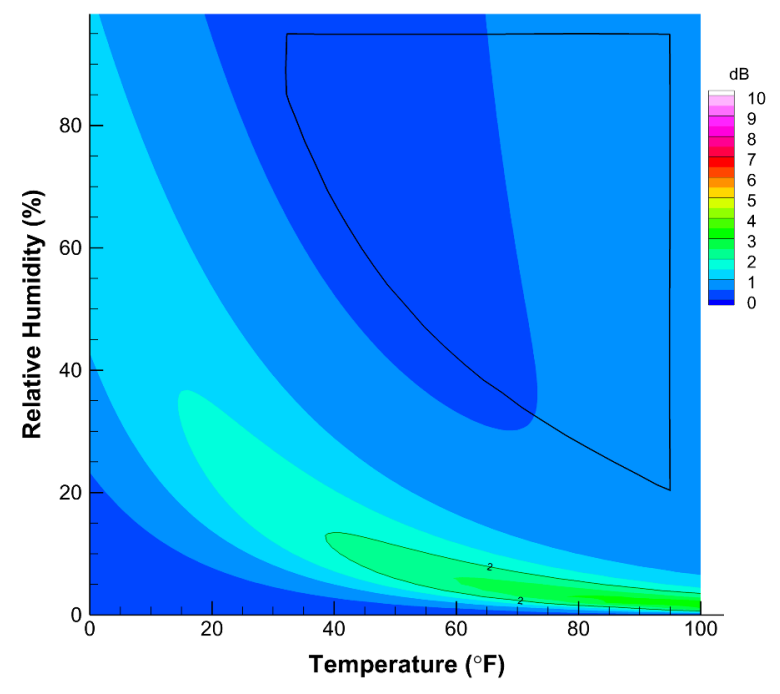

(a) $1 \mathrm{kHz}$

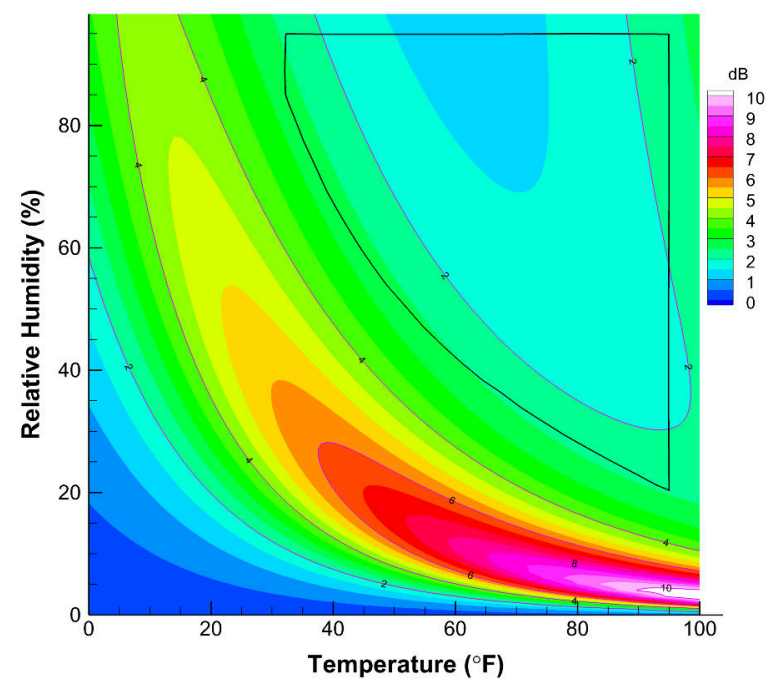

(c) $3 \mathrm{kHz}$

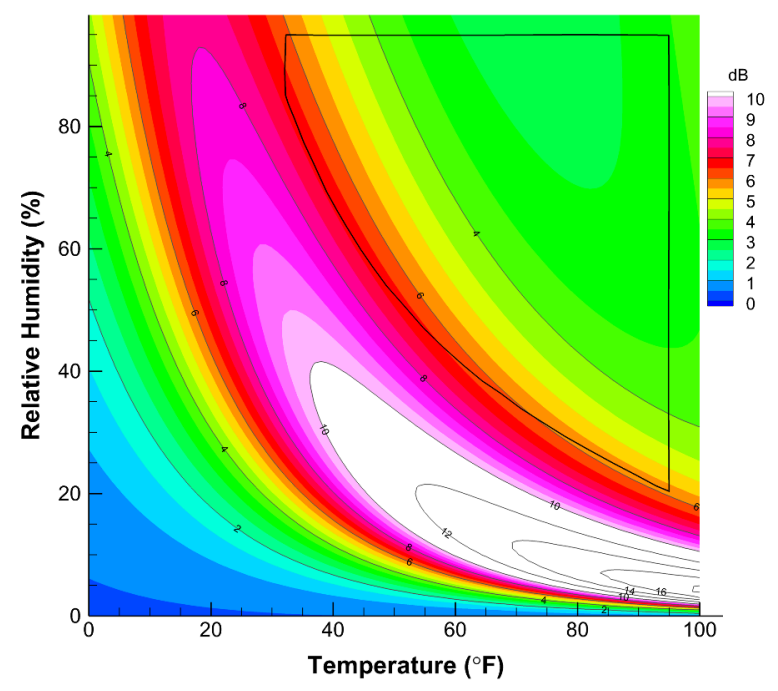

(e) $5 \mathrm{kHz}$

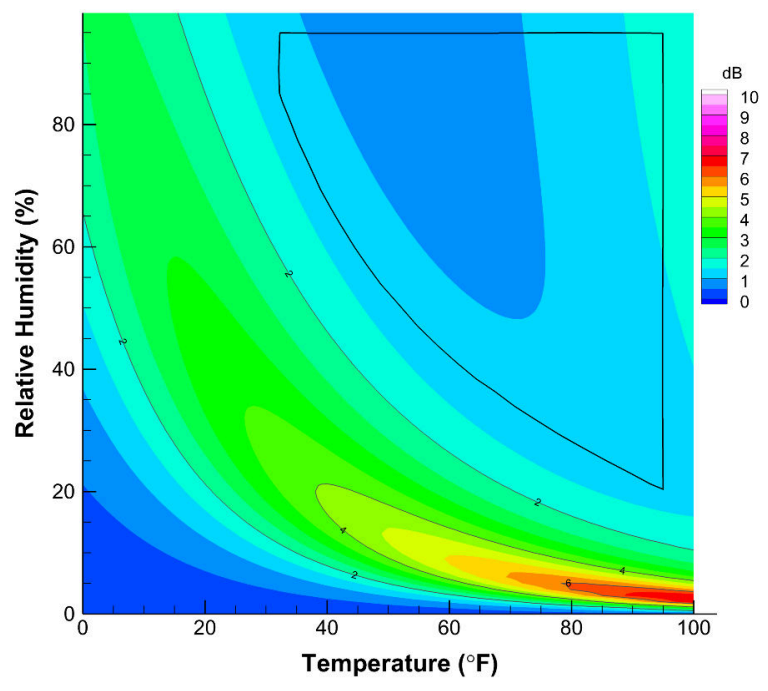

(b) $2 \mathrm{kHz}$

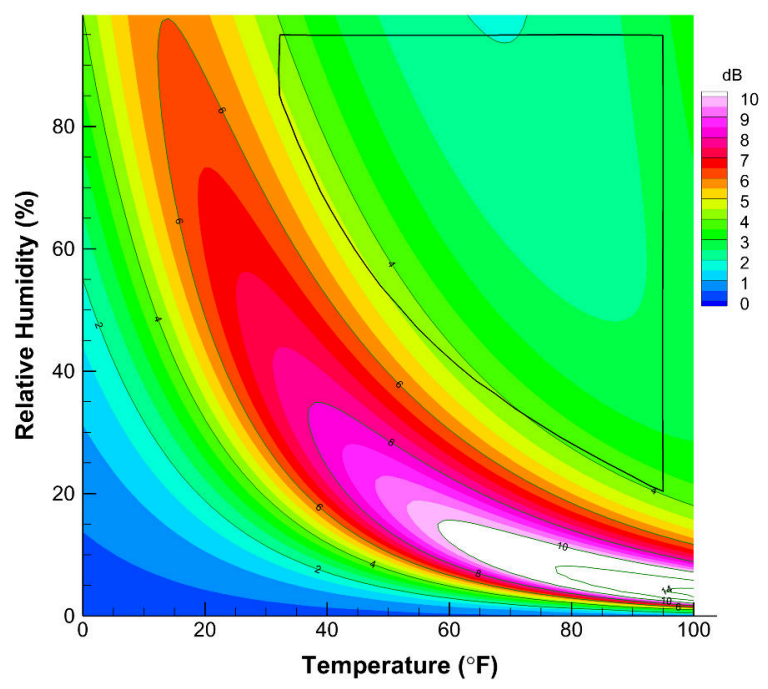

(d) $4 \mathrm{kHz}$

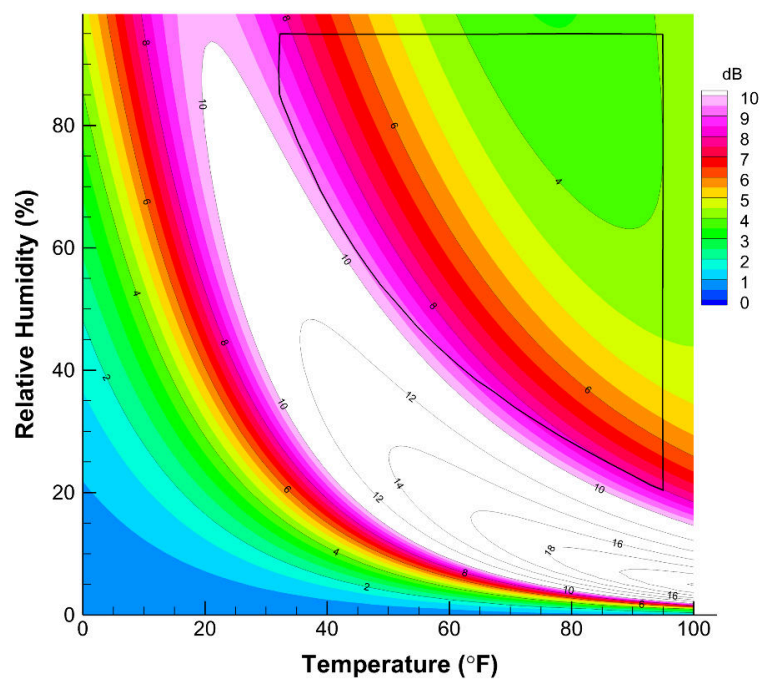

(f) $6 \mathrm{kHz}$

Fig. 2 Calculated atmospheric attenuation in $\mathrm{dB}$ for $328 \mathrm{ft}(100 \mathrm{~m})$ of propagation. White contours are saturated, and the maximum attenuation is over $20 \mathrm{~dB}$. 
instrumentation attached to a tethered aerostat. Two sensors were attached to the tether approximately $10 \mathrm{ft}(3 \mathrm{~m})$ apart. Figure 4 (a) shows an Anasphere SmartTether ${ }^{\mathrm{TM}}$ Version 8.0 atmospheric profiling system attached to the aerostat, and Fig. 4 b) shows the aerostat during a launch. The SmartTether ${ }^{\mathrm{TM}}$ system, in addition to recording temperature, relative humidity and pressure data, allowed for wind profile measurements through use of cup anemometers for wind measurements - though that proved problematic. Anomalous readings were common in light wind conditions, often times showing unrealistic spikes in wind speed measurements when winds were in fact calm. Furthermore, the temperature and relative humidity sensors were exposed on the underside of the housing unit increasing susceptibility to strong radiative heating in the desert environment. When the system was near the ground, the reported temperature and relative humidity did not agree with the two ground stations, instead often reading significantly higher values. The data was adjusted to match the ground weather stations, and only the deltas with altitude were used in the atmospheric corrections.

To alleviate some of the issues with the SmartTether ${ }^{\mathrm{TM}}$ system, additional instrumentation was tested during the 2016 deployment, which led to this new instrumentation being incorporated for 2017. Radiosondes, frequently employed at NASA AFRC, are commonly used to perform atmospheric soundings from the ground up to high altitudes. Normally a single-use instrument unless recovered, radiosondes are attached to an aerostat to allow for the capability to collect values of atmospheric pressure, temperature, relative humidity, wind speed and wind direction as it ascends through the atmosphere. The traversing motion of the instrument as it ascends equates to a calculated wind speed and direction value. In this application, however, the radiosondes were attached to the tethered aerostat allowing for the instruments to be reused, but rendering the wind data unusable. Nonetheless, the temperature and relative humidity measurements obtained from a Vaisala ${ }^{\circledR}$ RS92 radiosonde (shown on the left of Fig. 5) were found to agree well with the ground stations and provide profile data that was consistent between ascents and descents.

In 2017, the Vaisala ${ }^{\circledR}$ RS41 radiosonde, a smaller unit in comparison to the RS92 as seen in Fig. 5, provided newly advanced instrument specifications. To accommodate the recommended ascent rate for this instrument, $19.7 \pm 9.8 \mathrm{ft} / \mathrm{s}$ $(6 \pm 3 \mathrm{~m} / \mathrm{s})$, a new winch was obtained that could allow ascent rates in this range. Two sensors were used simultaneously to provide redundancy in data collection, aiding in quality checking.

Wind data was obtained using an Atmospheric Sciences Corporation Mini-SoDAR 4000 seen in the lower left corner of Fig. 4(b). This instrument served as a wind profiler, configured to report wind speed and direction in $16.4 \mathrm{ft}(5 \mathrm{~m})$ intervals between 98 and $656 \mathrm{ft}$ ( 30 and $200 \mathrm{~m}$ ). The SoDAR (Sonic Detection and Ranging) instrument operates by first emitting an audible pulse, then recording the atmospheric echo it receives from the interaction of sound with atmospheric turbulence. By measure of the frequency (Doppler) shift of the echo, wind data is thus calculated. The unit was located where it did not interfere with the measurements of the microphone array, allowing the winds to be tracked throughout the test. Wind conditions below $98 \mathrm{ft}(30 \mathrm{~m})$ were measured with both ground weather stations.

\section{Single-Microphone Results}

Two Gulfstream ${ }^{\circledR}$ III aircraft made passes over the microphone array during the flight tests. The primary aircraft has a tail number of 804 and has an adaptive compliant trailing edge (ACTE) flap installed that morphs like a bird's wing instead of translating and rotating like a traditional flap. 804 also has onboard instrumentation to measure and record important parameters like the true airspeed and aircraft attitude. The 804 aircraft is shown in Fig. 6. The other Gulfstream ${ }^{\circledR}$ III has a tail number of 808 and is in a standard configuration with a Fowler flap. The 808 aircraft currently does not have any extra instrumentation to record flight data other than a differential GPS.

An example of the atmospheric data collected using Vaisala ${ }^{\circledR}$ RS92 radiosondes on September 29 and October 4, 2016 is shown in Figs. 7 and 8 . The time is given in Pacific Standard Time (PST) and Coordinated Universal Time (UTC) seconds of the day (SOD). These plots were generated within a few minutes of each aerostat ascent and used to assess whether the atmospheric conditions warranted continuation of the day's flights. The left plot shows the temperature vs relative humidity with the recommended range shown by the green line. Each blue square represents the average measurement over a $25 \mathrm{ft}(7.6 \mathrm{~m})$ layer, and the red circle is the average value from the ground to an altitude of $400 \mathrm{ft}$ $(122 \mathrm{~m})$. The radiosonde altitude is calculated using the hypsometric equation[12] for non-standard day atmospheric conditions, incorporating the pressure and the virtual temperature. Use of this equation yields more accurate altitude resolution near the surface as opposed to relying on the instrument's GPS position, which is preferable for high-altitude flight not experienced in this application. The right two plots in Fig. 7 show the temperature and relative humidity versus the altitude, with the symbols indicating the average values up to $400 \mathrm{ft}(122 \mathrm{~m})$.

The temperature profiles from both days exhibit temperature inversions of around $5{ }^{\circ} \mathrm{F}\left(2.8^{\circ} \mathrm{C}\right)$ between the ground and $500 \mathrm{ft}(152 \mathrm{~m})$. The temperature and relative humidity throughout the profile were within the desired range on 092916 , but they were just outside the range on 100416. Hence, the atmospheric attenuation was higher on 100416.

On both September 29 and October 4, 2016, the 808 Gulfstream ${ }^{\circledR}$ III aircraft made passes over the array at a speed of 150 knots with the Fowler flap set at $20^{\circ}$ and the landing gear deployed. While the aircraft was near the array, the 


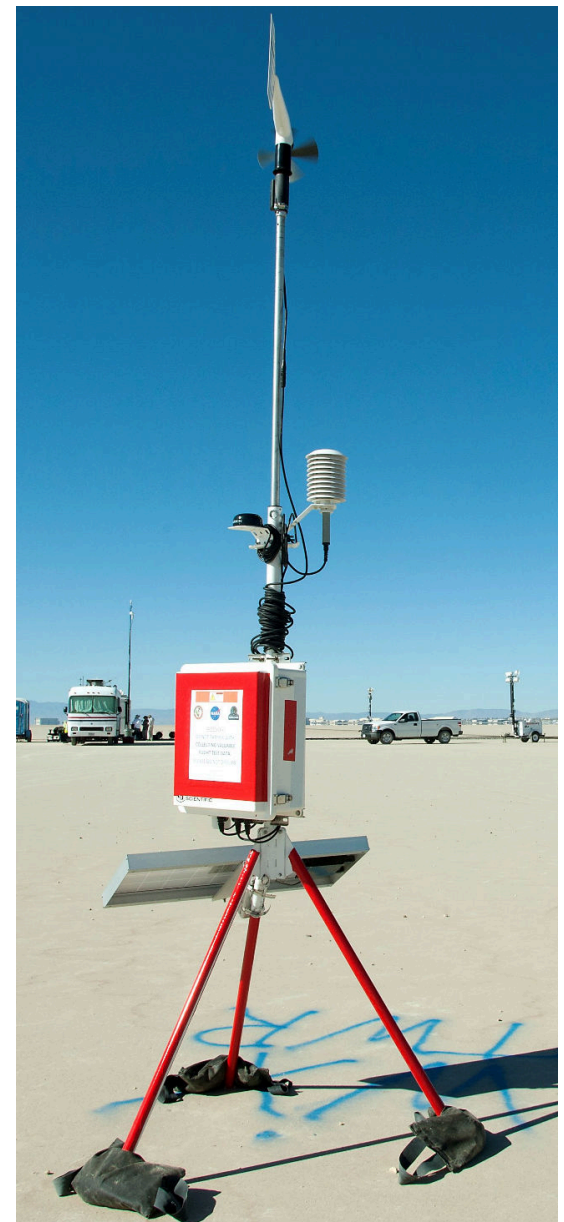

(a)

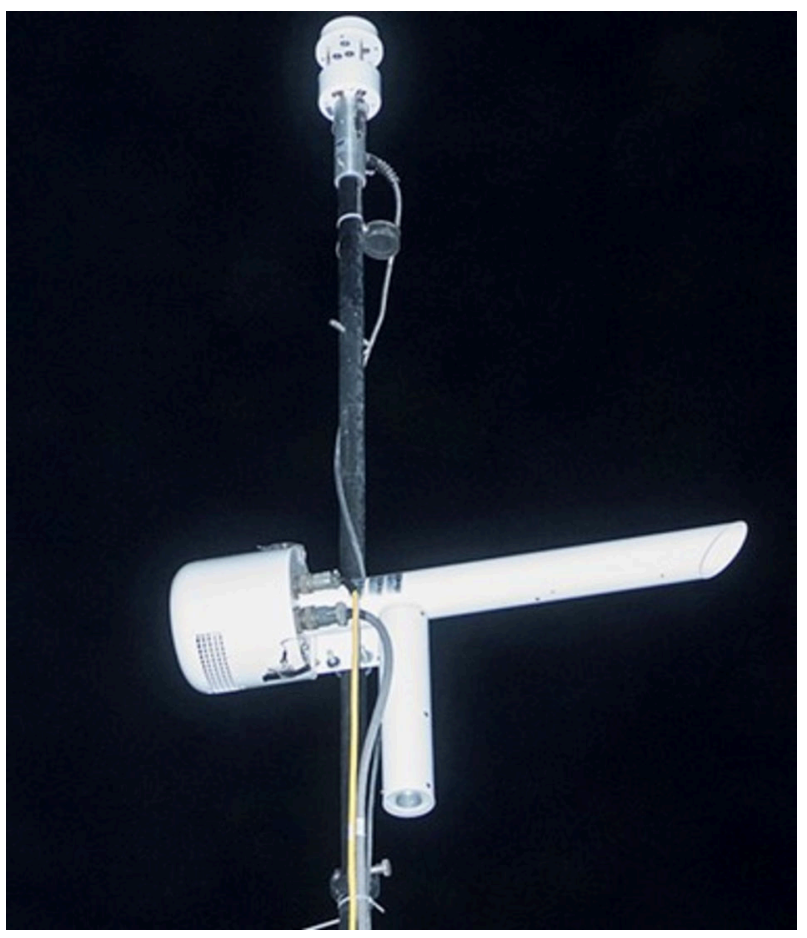

(b)

Fig. 3 Ground measurement suites.

engines were at ground idle (throttle at $0 \%$ ) for all of the airframe noise testing. The passes that occurred within a few minutes of the aerostat ascents used to collect the data in Figs. 7 and 8 are denoted by 092916_008 and 100416_018, respectively, where the pass number is after the under bar. The atmospheric data for passes is obtained by interpolating between the hourly observations bracketing the time of a pass. For these two passes, the uncorrected spectra from the center microphone in the array were compared to the background in Fig.9.a). The solid lines in Fig.9 9 b) indicate corrected data, which means that the attenuation calculated using the layered atmospheric observations has been added to the spectra. Hence, the corrected spectra are basically lossless with respect to atmospheric attenuation. Such spectra could be compared directly to computational simulation results of the same aircraft configuration, but would need to have some attenuation subtracted back off to compare with experimental data that hasn't been similarly made lossless. These narrow band spectra were computed with a $37.5 \mathrm{~Hz}$ bin width, but are presented as power spectral density (PSD) in $\mathrm{dB}$ per Hz. The spectra correspond to 0.5 seconds of data collected when the aircraft was nearly overhead with respect to the center of the array. In addition, the solid red line shows the background noise levels obtained when the aircraft was far from the array. Below 2 $\mathrm{kHz}$, the background is influenced by road noise from a highway, but electronic noise sets the level at higher frequencies. The uncorrected spectrum in 100416_018 is within a few dB of the background above $6.5 \mathrm{kHz}$, which results in the corrected spectrum actually rising at high frequencies. The corrected spectrum for 092916_008 doesn't rise appreciably but, for the same reason, flattens out above $9 \mathrm{kHz}$. A low-pass filter was applied with a corner frequency of 10kHz, likely affecting frequencies above $8 \mathrm{kHz}$. Below $6 \mathrm{kHz}$, the corrected data collapses quite well, especially when considering all of the parameters involved in flight testing.

A much less desirable atmospheric observation from the 2017 campaign is shown in Fig. 10 where the relative humidity was near $20 \%$ with a strong temperature inversion of around $14{ }^{\circ} \mathrm{F}\left(7.8^{\circ} \mathrm{C}\right)$. The 804 Gulfstream ${ }^{\circledR} \mathrm{III}$ aircraft was flown on this day with the ACTE flaps set at $25^{\circ}$. Multiple passes were completed at a speed of 150 knots with the landing gear deployed. Similar passes were also completed on the following day when the relative humidity was better but a 


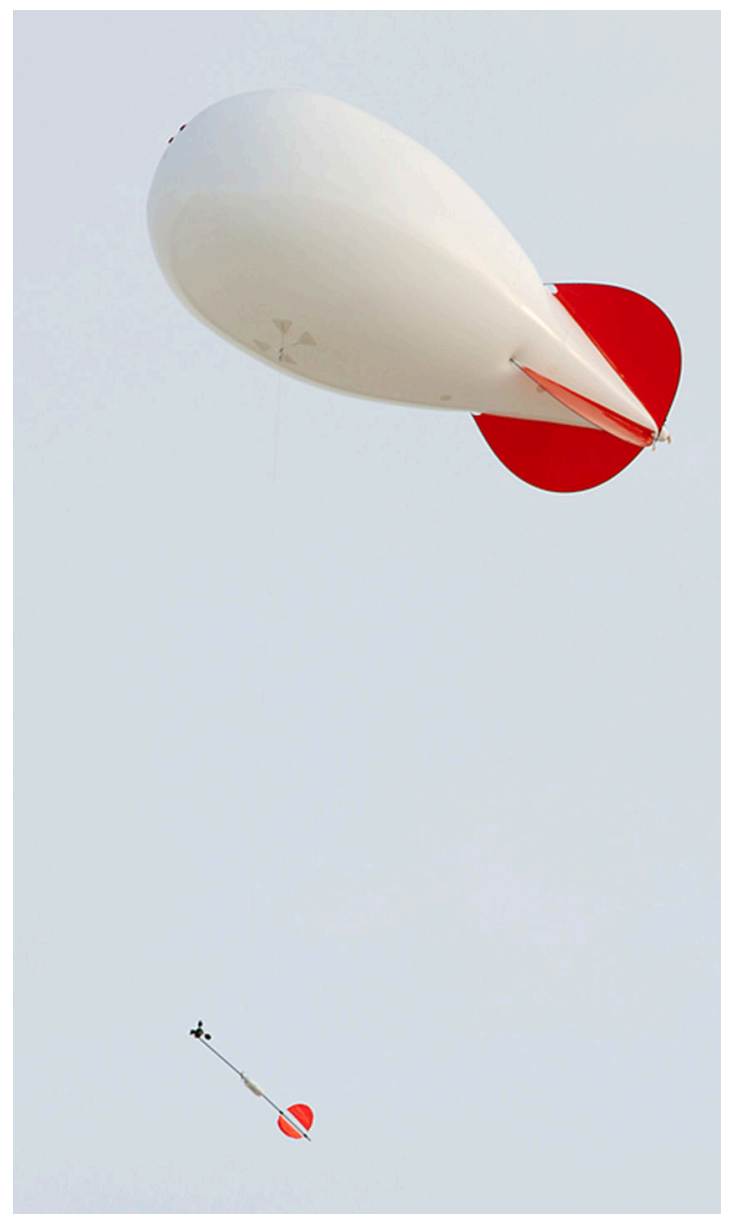

(a) 2016

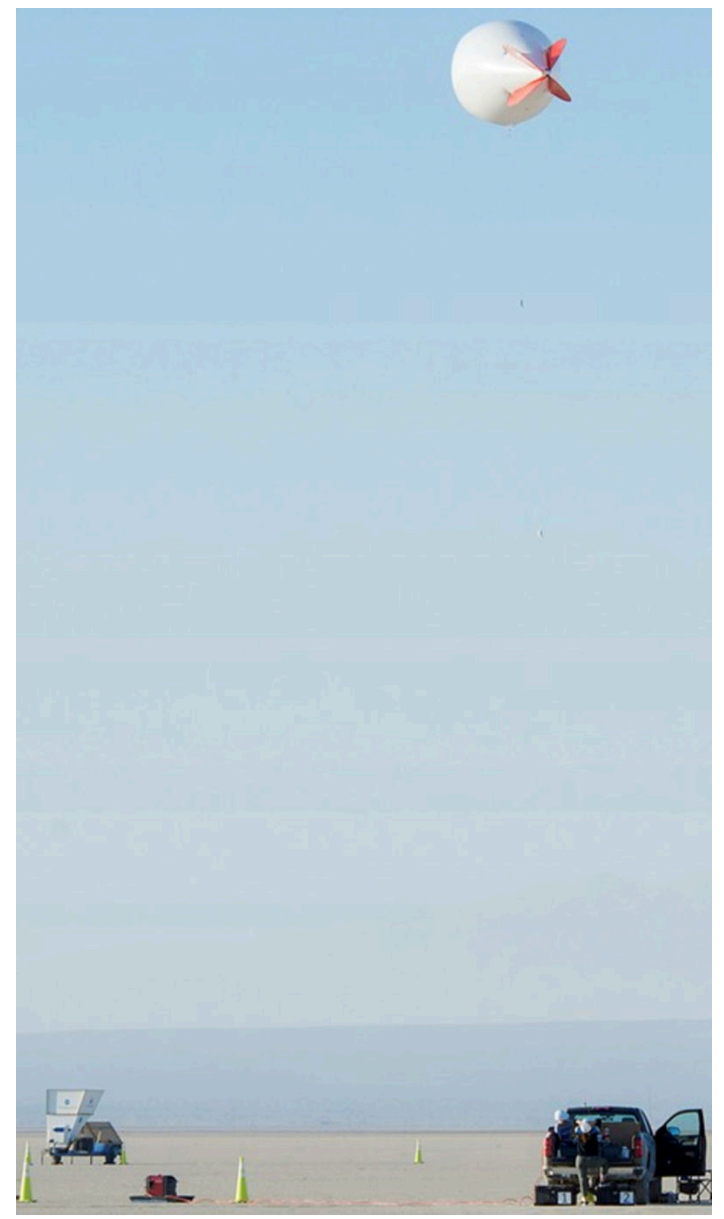

(b) 2017

Fig. 4 Aerostat measurements.

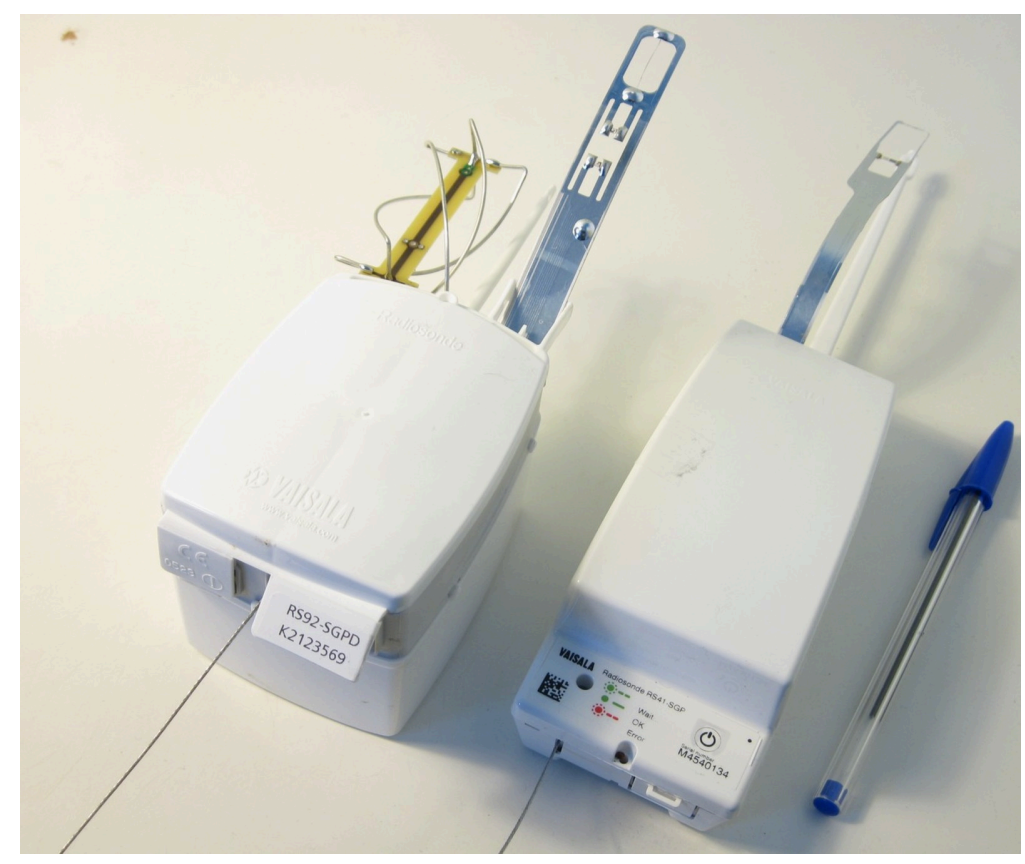

Fig. 5 Vaisala ${ }^{\circledR}$ RS92 (left) and RS41 Radiosondes. 


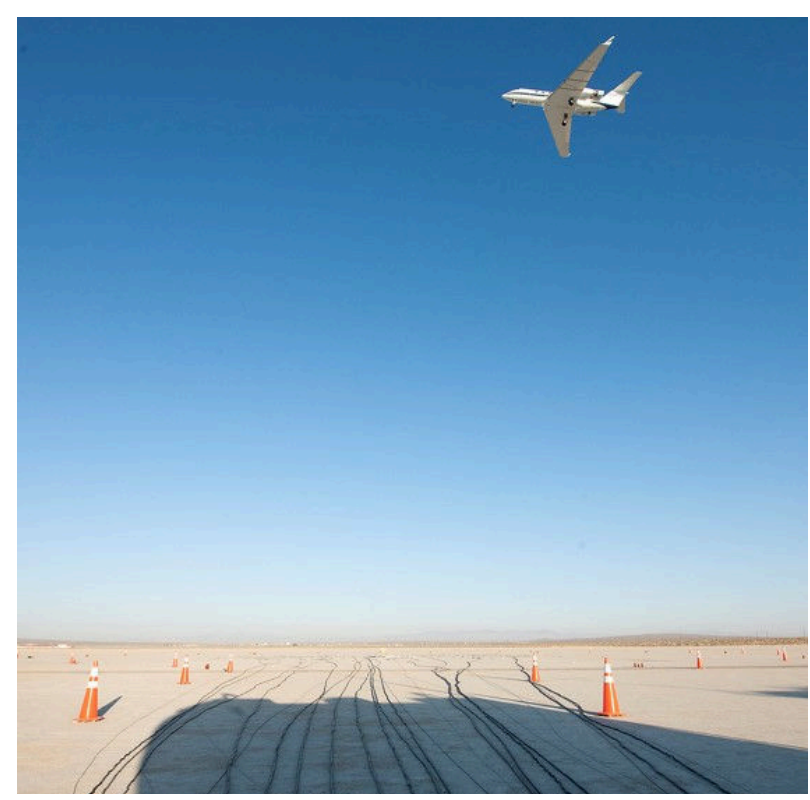

(a) Over Array

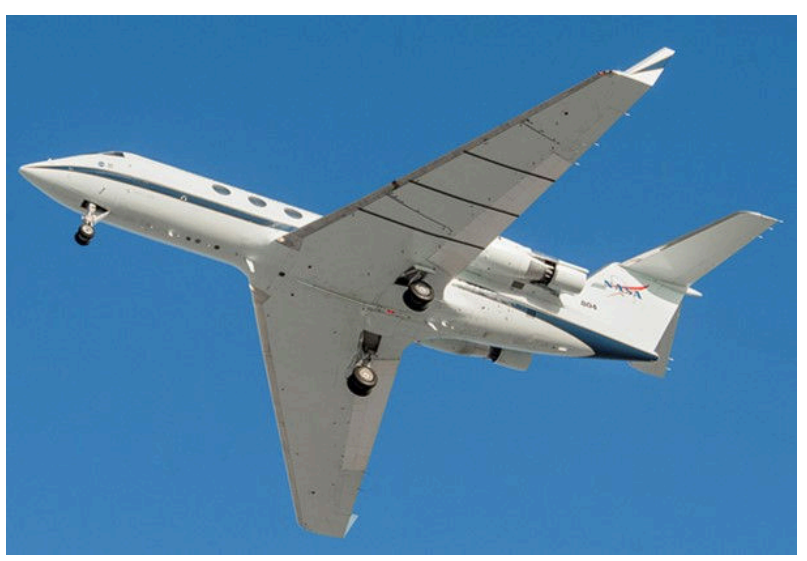

(b) Closeup

Fig. 6 Images of Gulfstream ${ }^{\circledR} \mathrm{III}$ in flight.
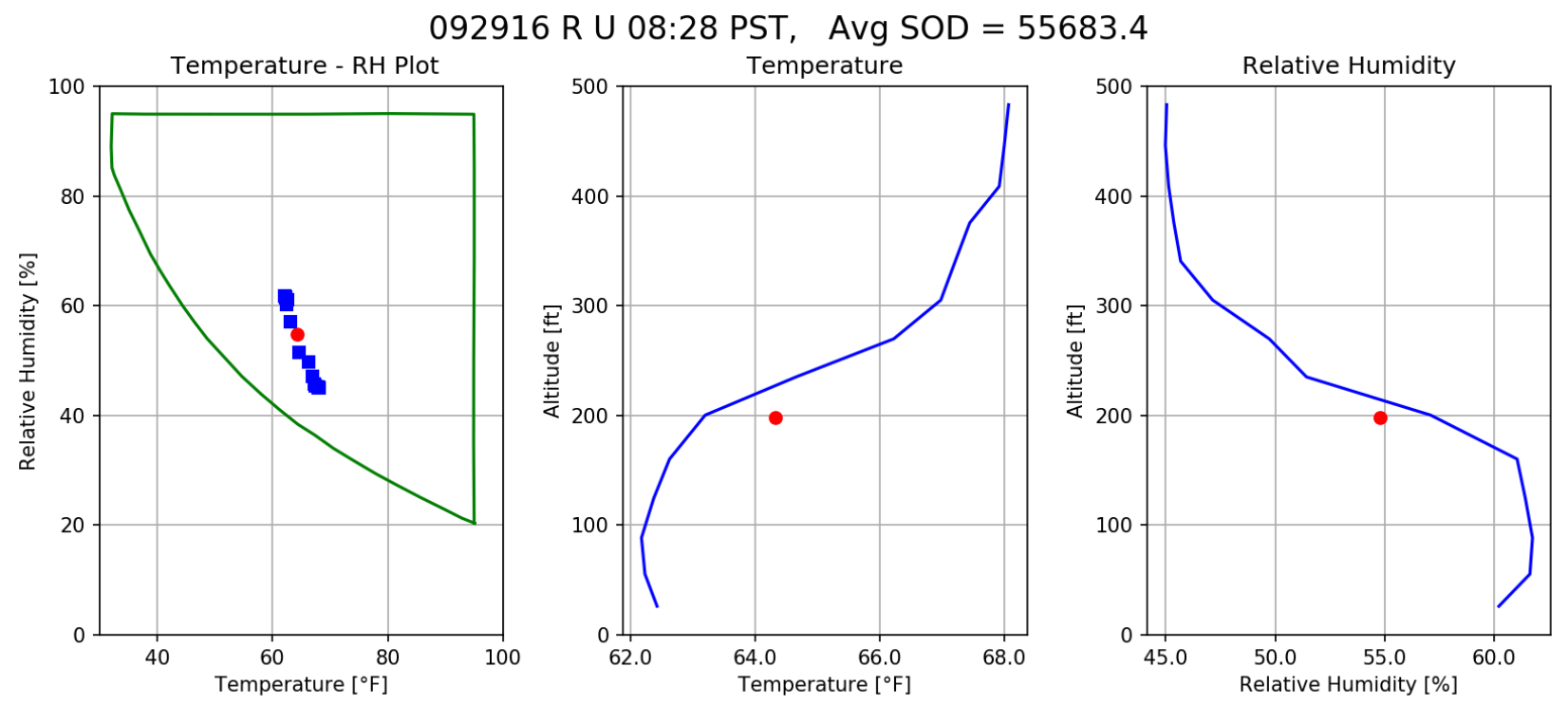

Fig. 7 Radiosonde measurements as a function of altitude on September 29, 2016.

strong inversion was still observed. The first atmospheric observations on those days are shown in Figs. 10] and 11, and the temperature and relative humidity for the different passes are compared directly in Fig. 12. As time progresses the temperature near the ground in Fig. 12 (a) is seen to increase and become more uniform, whereas, the relative humidity tends to decrease commensurately as Fig. 12,b) illustrates.

The uncorrected spectra from the center microphone in the array are compared in Fig. 13 (a). These spectra were obtained using the data acquired from a 0.5 second interval when the aircraft was nearly overhead of the center of the array. The two passes on October 11, 2017 agree fairly well, but some differences are apparent in the data from October 12. In particular, pass 007 colored in green is seen to be higher than the other two passes from the same day. However, all five of the corrected spectra collapse reasonably well up to $6 \mathrm{kHz}$ as seen in Fig. 13 (b). The agreement in the tone at 1 $\mathrm{kHz}$ is not as good, but the tone is caused by resonance in a small cavity on the landing gear that is very sensitive to the aircraft attitude and cross winds. Above $6 \mathrm{kHz}$, the spectra turn upwards, which is indicative of the signals hitting the noise 

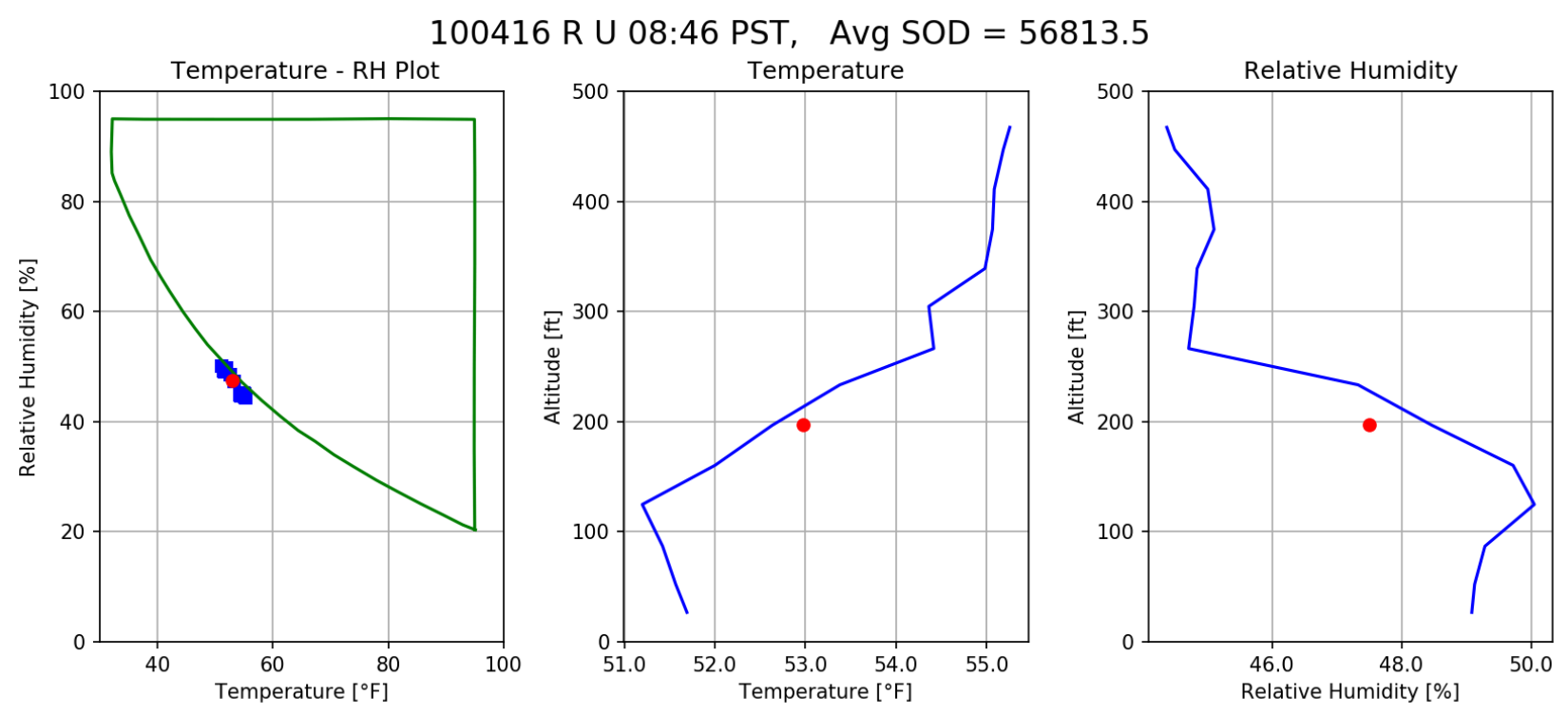

Fig. 8 Radiosonde measurements as a function of altitude on October 4, 2016.

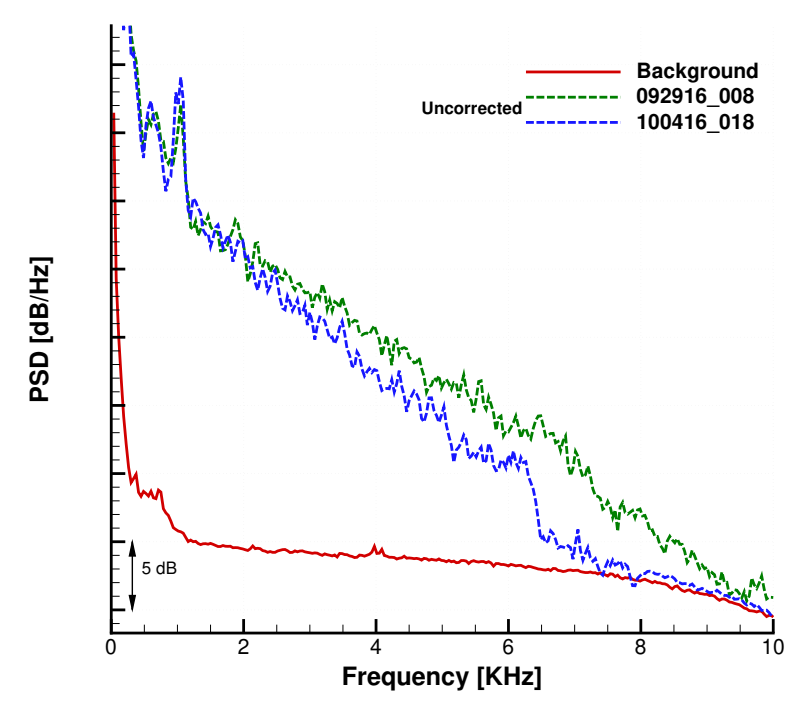

(a) Uncorrected

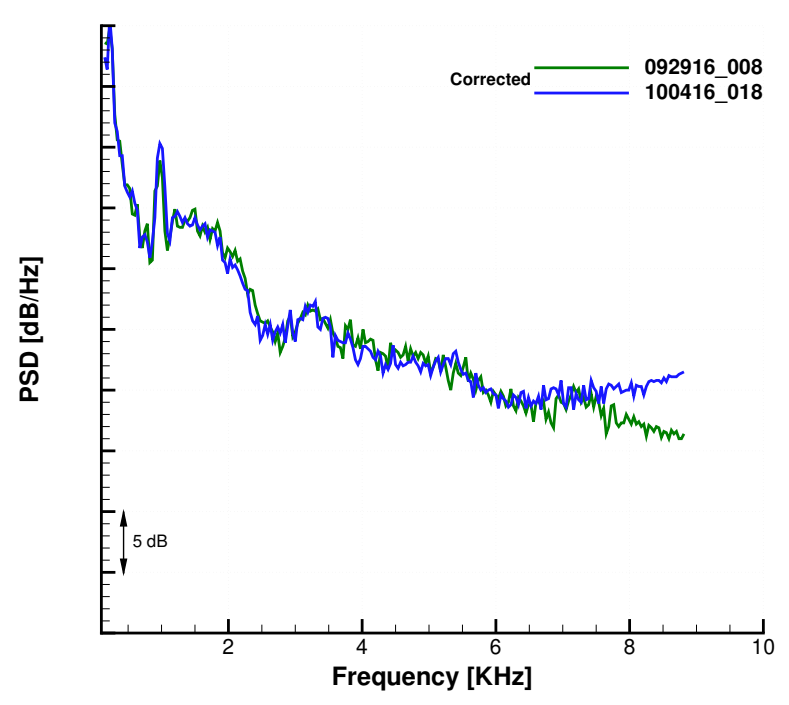

(b) Corrected

Fig. 9 Spectra from 808 passes with flaps at $20^{\circ}$ and landing gear deployed.

floor. When the aircraft is in a quieter configuration or farther from the array, the frequency at which the signal reaches the background occurs at lower frequencies. For the conditions on October 11, the background is reached at $3 \mathrm{kHz}$ for aircraft distances needed to perform noise certification measurements. Hence, such conditions would preclude meaningful single microphone measurements of the entire flyover, but some useful data can still be obtained when doing analyses over limited aircraft positions or with an array. 

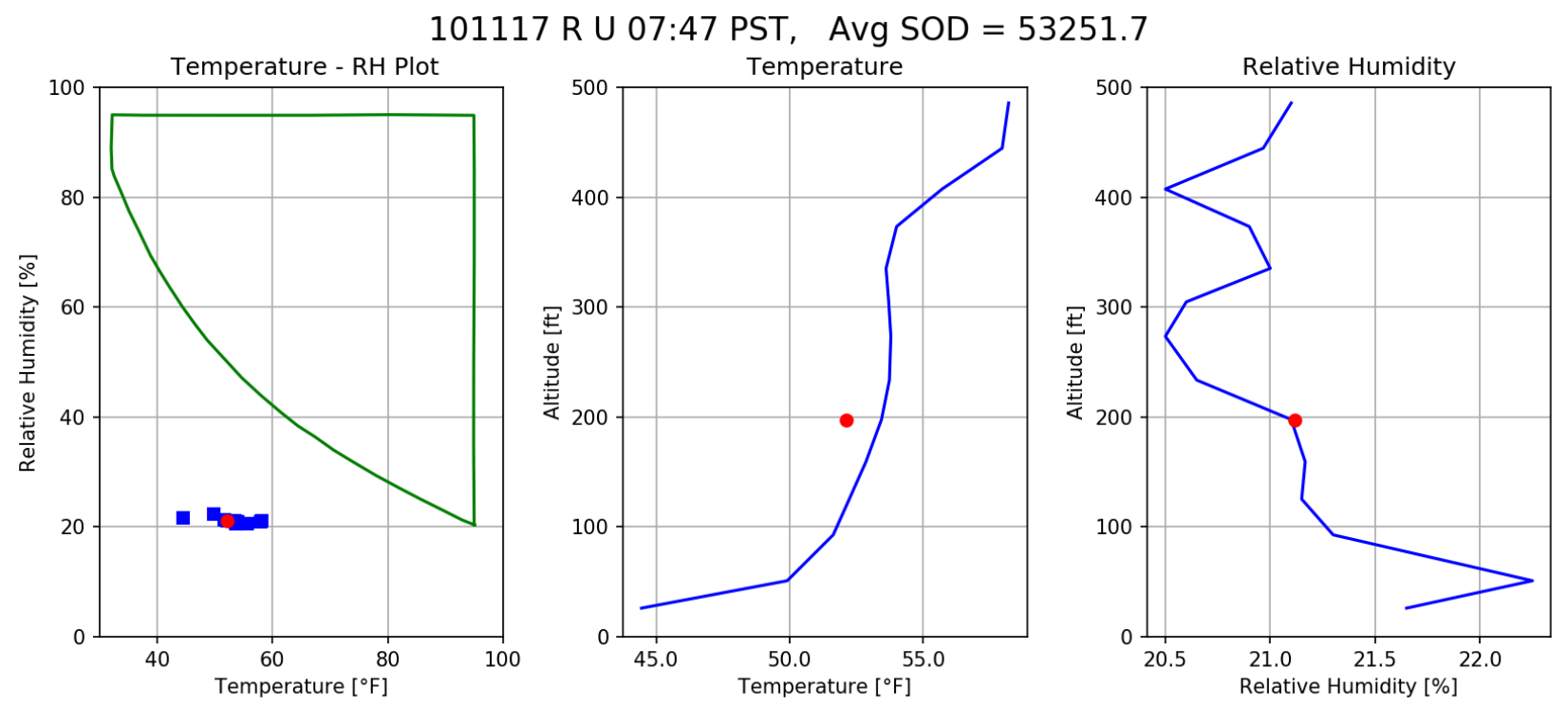

Fig. 10 Radiosonde measurements as a function of altitude on October 11, 2017.
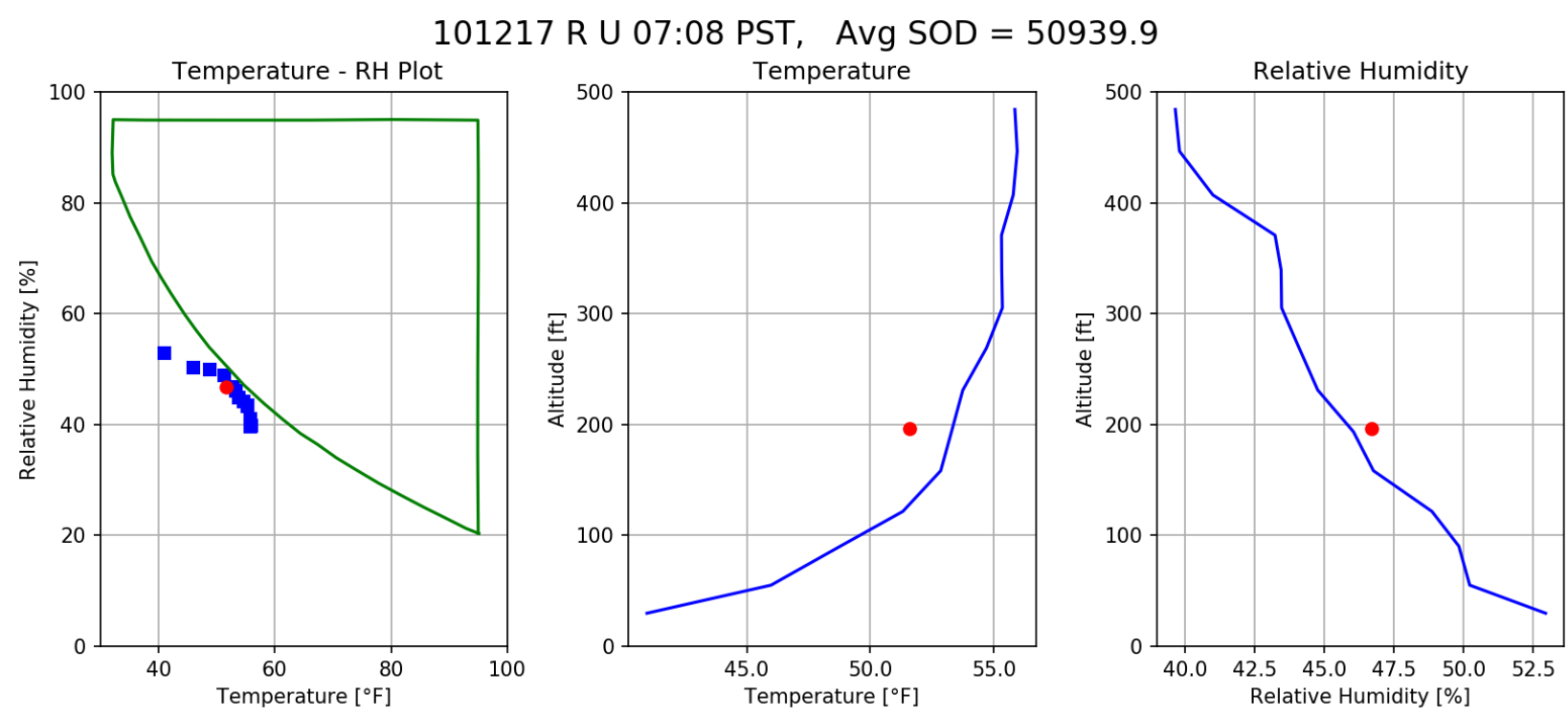

Fig. 11 Radiosonde measurements as a function of altitude on October 12, 2017. 


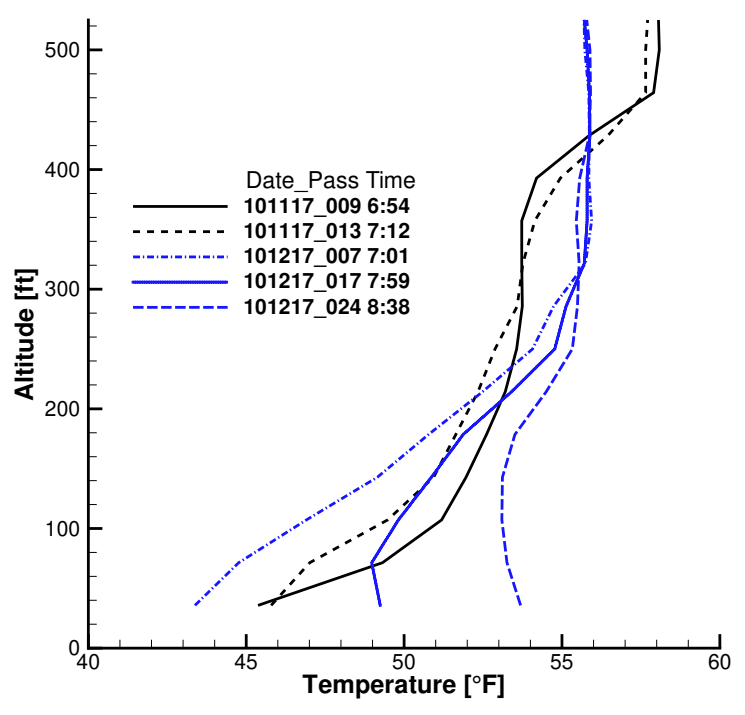

(a)

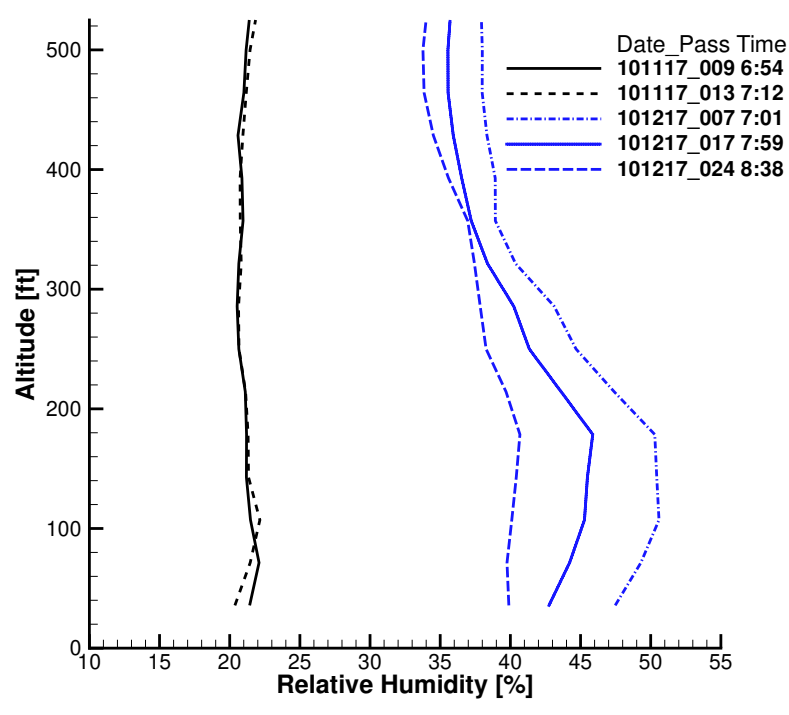

(b)

Fig. 12 Comparison of atmospheric observations as a function of altitude.

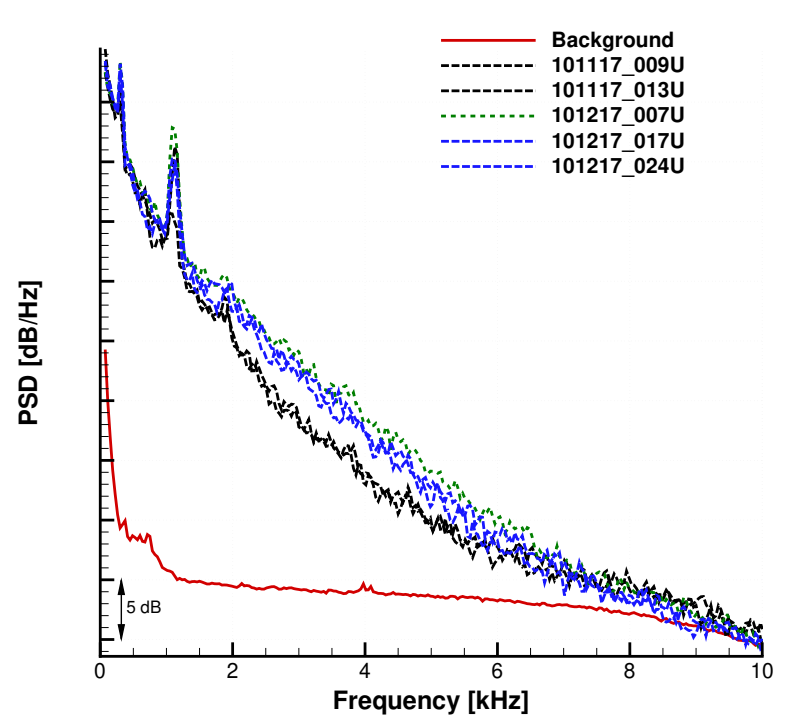

(a) Uncorrected

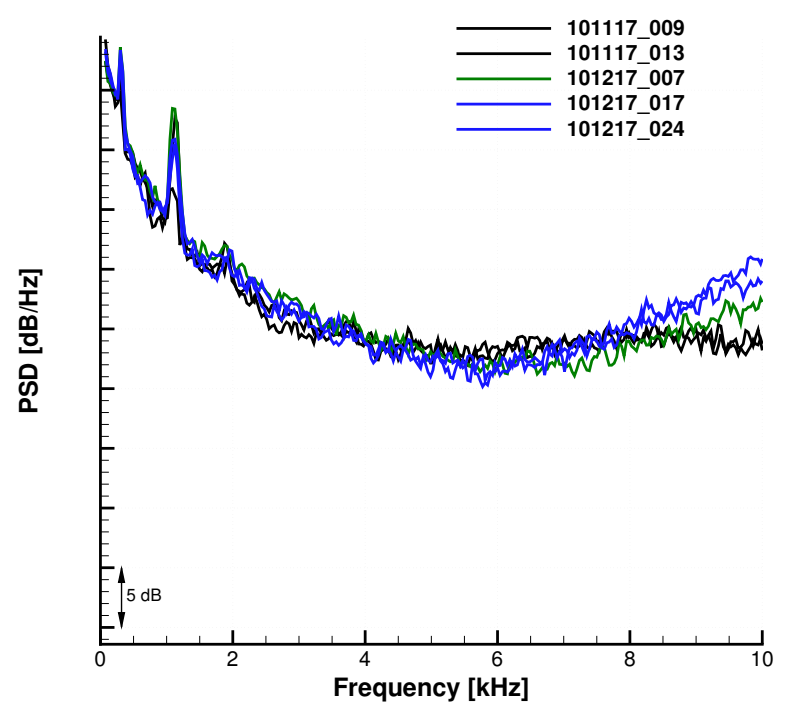

(b) Corrected

Fig. 13 Center microphone spectra from 804 passes with ACTE flaps at $25^{\circ}$ and landing gear deployed. 


\section{Array Results}

The comparisons in the previous section demonstrate that the corrections for atmospheric absorption can collapse data from days with very different meteorological conditions. However, the number of passes presented was limited, and only single microphone data was analyzed. The purpose of a microphone array is to use array beamforming to isolate noise sources from different geometric regions. In this section, every available pass with a speed within $\pm 5 \mathrm{kn}$ of the target $150 \mathrm{kn}$ is included in the comparisons, and the spectra are obtained by integrating array beamform maps. The interval with the aircraft $\pm 50 \mathrm{ft}(15 \mathrm{~m})$ in the direction of flight from the center of the array was used in the processing. Beamforming with diagonal removal[13, 14] was applied with array shading[15], followed by deconvolution using the CLEAN algorithm[16, 17]. Spectra are obtained by integrating the CLEAN beamform maps (summing the $p^{\prime 2}$ values), with a cutoff of $10 \mathrm{~dB}$ below the peak. Anything more than $10 \mathrm{~dB}$ below the peak is likely to be a sidelobe and is neglected. The attenuation correction was not applied within the beamforming process, e.g., as an amplitude modification to the steering vectors, as the correction is known based on frequency but the beamforming is performed in the time-domain. Instead, the correction was applied to the array beamforming results for each of the 29 blocks (in time) computed over the interval with the aircraft within $\pm 50 \mathrm{ft}(15 \mathrm{~m})$ above the center of the array. For each block, the attenuation over the average distance from the aircraft to the center of the array was computed, and this was added into the result. The spectra shown were obtained from an average over the 29 blocks.

Figure 14 shows the integration region of interest: a polygon that encompasses the wing region. The leading edge of the wing is excluded because engine fan tones scatter off the leading edge of the wing, especially for beamforming locations where the aircraft is approaching the array. Also, the fuel vapor vents near the wing tips can be very loud at frequencies around $250 \mathrm{~Hz}$. In addition to this integration region, the grid around the whole aircraft was integrated.

804 passes with the ACTE flaps at $25^{\circ}$ are available from six days and multiple passes on each day. The temperature and relative humidity observations from these six days are presented in Fig. 15.a), where the first measurement of the day is shown as squares and the last as circles. Each symbol represents the average of the aerostat measurements over $25 \mathrm{ft}$ $(7.62 \mathrm{~m})$ in altitude. The desired temperature-relative humidity range is indicated by the solid black line. Of the six days, two are well within the desired range, two are marginal, and two are well outside.

The magnitude of the surface winds from the same days are shown in Fig. 15.b). These values were obtained by averaging the measurements from the two ground stations. Although the average winds over the vertical profile from 0 to $400 \mathrm{ft}$ was used in the data processing, those data are only available from the hourly aerostat launches; whereas, the ground stations provided continuous monitoring of the winds. The figure shows that, in general, the variation in the wind speed magnitude is similar across the days except for 100317, which had higher wind speeds. Although the winds were included in the steering vectors during beamforming, their inclusion did not improve the results. The spatial and temporal variability in the winds most likely makes their use impractical.

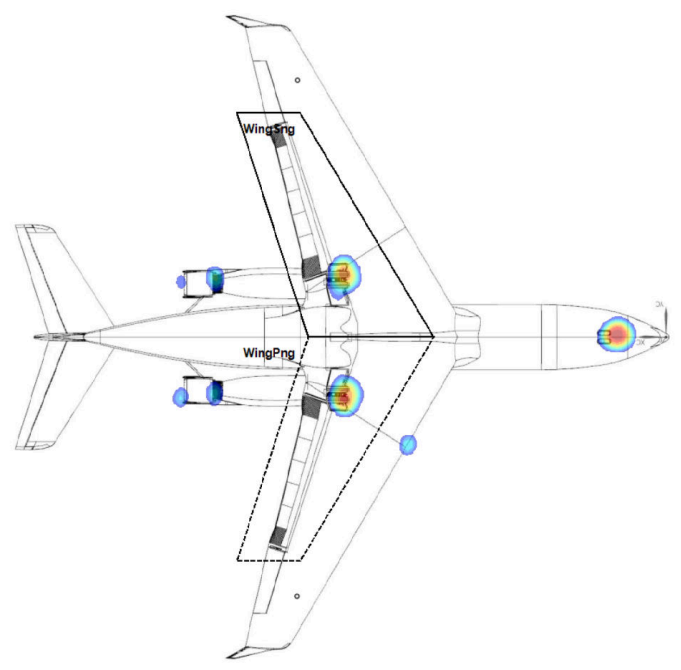

Fig. 14 Integration region used with beamforming.

Array integrated spectra are shown in Fig. 16 comparing the wing region to the whole aircraft. The spectra are shown in $1 / 3$ octave bands because the narrow band spectra are very oscillatory, making a comparison of so many passes difficult. The amplitudes have all been normalized to a common aircraft height of $394 \mathrm{ft}(120 \mathrm{~m})$ based on $p^{\prime} \propto 1 / r$, where $p^{\prime}$ is the perturbation pressure of the noise signal and $r$ is the distance between the aircraft and the center of the array. The solid lines in Fig. 16 represent good meteorological days (those within the recommended limits of McCollough and True[7]), 


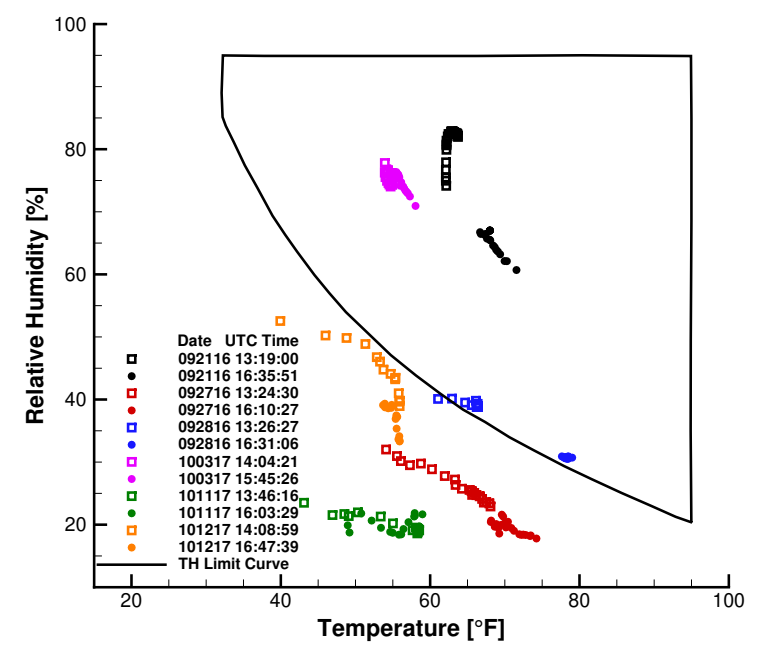

(a) Temperature-Relative Humidity

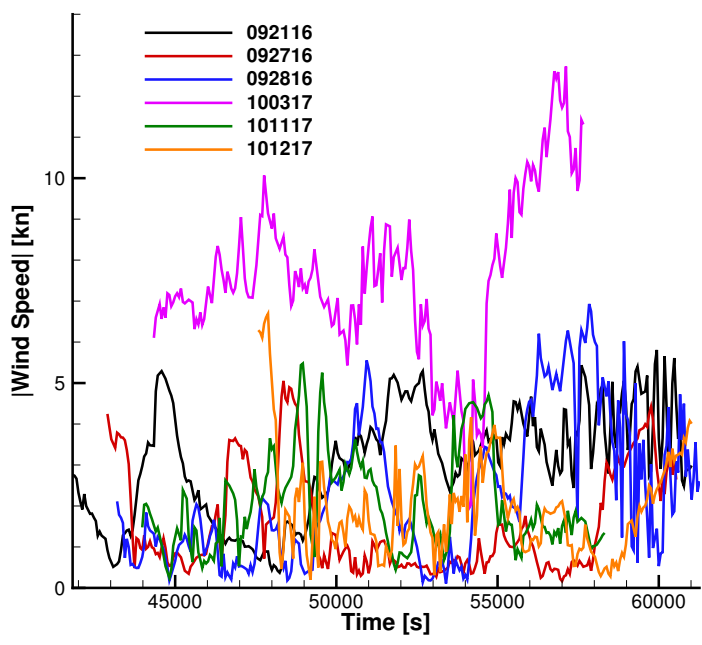

(b) Wind

Fig. 15 Atmospheric observations from all of the days with 804 passes with ACTE flaps at $25^{\circ}$ and landing gear deployed.

and the dashed lines are for marginal days. The dotted lines indicate meteorological conditions that fall well outside of the desired range. The spectra in Fig. 16 (a) indicate that above $3 \mathrm{kHz}$, the noise from the engines dominates when the whole grid is integrated, but the levels continue to fall off when just the wing region is used. However, the noise from the landing gear region eventually falls more than $10 \mathrm{~dB}$ below that of the engines at higher frequencies, and the integration becomes invalid. Although the integration cutoff is $10 \mathrm{~dB}$, the $10 \mathrm{~dB}$ is taken from the region being integrated. When the peak is outside of the integration region, values are included in the sum that could be sidelobes of peaks outside the region. The problem is exacerbated by the background noise levels. Array beamforming can isolate aircraft noise from below background levels, but the rejection of the background is dependent on the effective number of microphones (based on the shading algorithm), array design and the background noise amplitudes. Spectra from microphone arrays should be interpreted by looking at the corresponding beamform maps.

Nonetheless, the noise from the wing region was found to be more consistent and could be collapsed more readily. The engines include vents for cooling, air conditioning, and auxiliary power generation. These sources do not scale with the speed of the aircraft, and were difficult to collapse across passes. The purpose of this paper is to examine the effect of meteorological conditions on flight test measurements, and the wing region makes it easier to isolate the impact of the atmosphere and minimize the influence of competing factors.

The passes included in the comparisons have true air speeds of $150 \pm 5 \mathrm{kn}$. The amplitude of noise from the gear and flaps is expected to scale with the sixth power of the velocity, so the spectra have been adjusted in Fig. 17. and the collapse is slightly improved. However, using a Strouhal scaling for the frequency in Fig. 17)(b) does not improve the comparison. Hence, only the amplitude scaling will be used in the remainder of the paper.

Beamform maps from the best (092116) and worst (092716) meteorological days (in terms of temperature and relative humidity) from 2016 are compared in Figs. 18 and 19 . The beamform grid has $201 \times 201$ points covering $100 \times 100$ feet. When deconvolving the beamform maps with the CLEAN algorithm[16, 17], sources are often reduced to a single grid cell, which is difficult to visualize. Therefore, the CLEAN resolution parameter was set to $2 \mathrm{ft}$ to obtain maps that would allow the sources to be identified more easily. However, the maps generated with the resolution parameter set to zero were used to integrate the maps and obtain spectra. The maps are presented with a range of 0 to $-10 \mathrm{~dB}$, where $0 \mathrm{~dB}$ represents the peak SPL value at that frequency, and $-10 \mathrm{~dB}$ is $10 \mathrm{~dB}$ below the peak. Each frequency map for each pass has it's own peak SPL, so only relative amplitude variations can be compared across passes or frequencies. The true intensity of a source is a combination of the level and the spatial extent of the source, as both parameters are used to integrate the maps and obtain spectra. However, $\mathrm{SPL}=10 \log \left(p^{\prime 2} / p_{\text {ref }}^{2}\right)$ values are not integrated directly, but instead the $p^{\prime 2}$ values. Hence, values near the peak will have the strongest impact on the integrated spectra.

The 1/3 octave band maps shown in Fig. 18 show sources starting at $200 \mathrm{~Hz}$, where the cavities for the main landing gear and fuel vapor vents (near the wing tips) are seen as the primary sources. The fuel vapor vents create loud tones centered around $250 \mathrm{~Hz}$, and the tones are sensitive to cross flow and airplane yaw. Although at least one of the vents is almost always a loud source, the other can be relatively weak, depending on the pass. In this case, they are similar in 


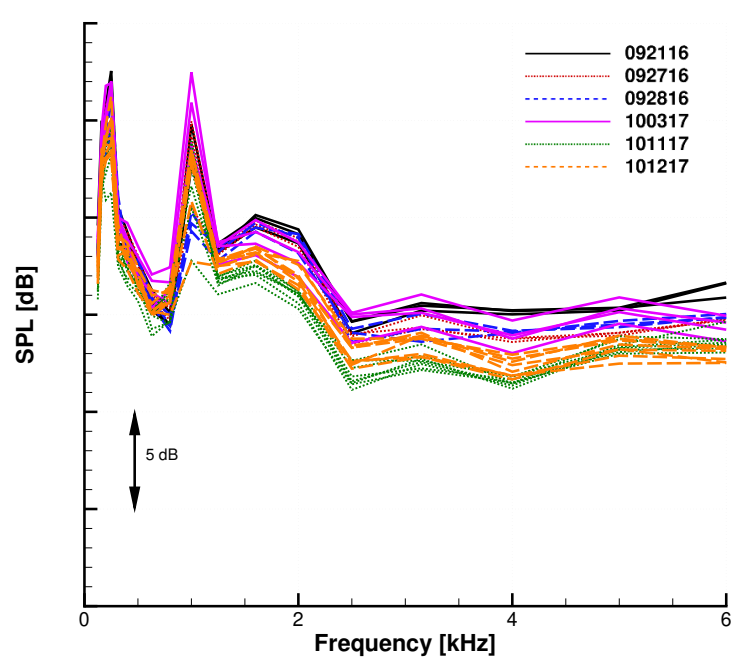

(a) Whole Aircraft

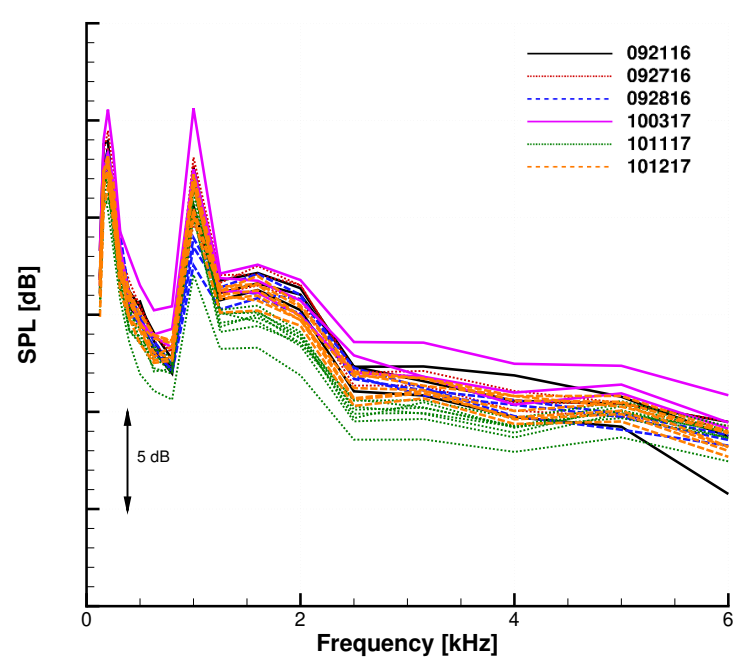

(b) Wings

Fig. 16 Integrated spectra from the different regions for 804 passes with ACTE flaps at $25^{\circ}$ and landing gear deployed. Layered corrections applied.

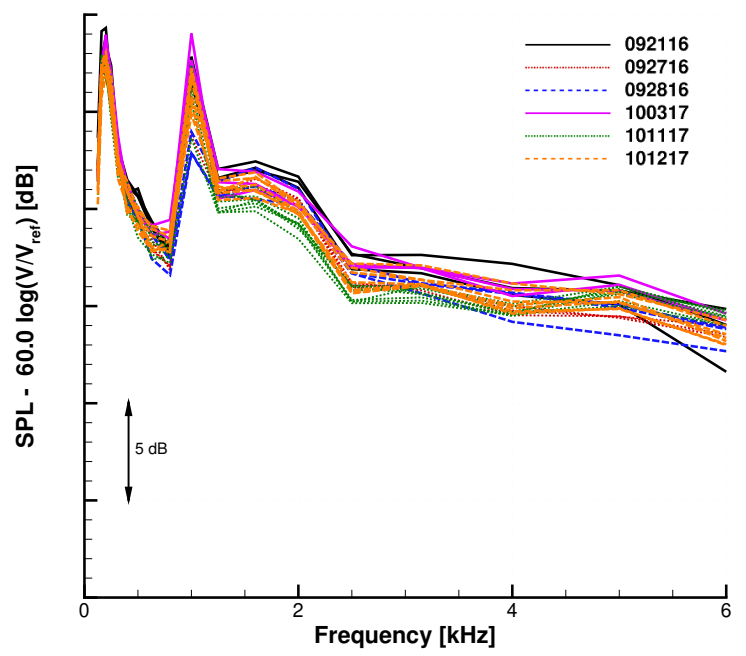

(a) Amplitude

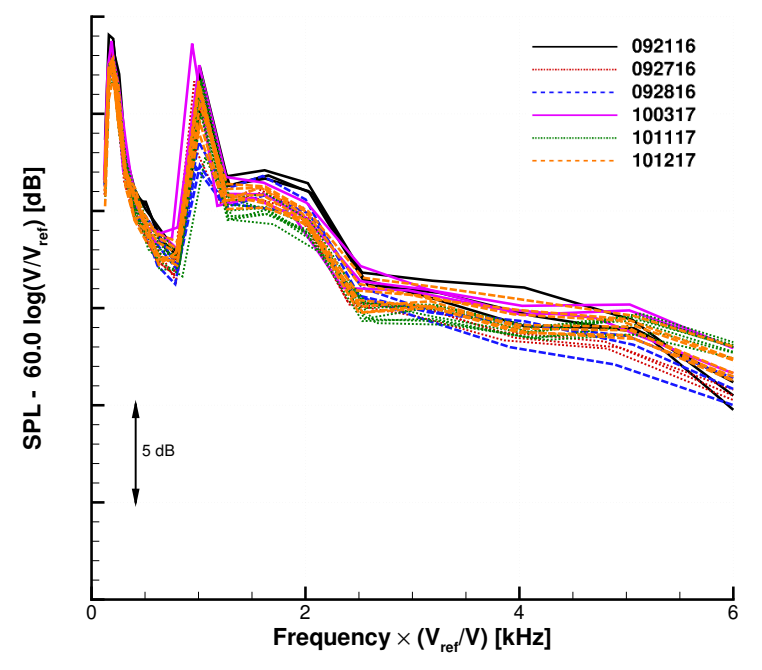

(b) Amplitude and Frequency

Fig. $171 / 3$ octave integrated spectra from 804 passes with ACTE flaps at $25^{\circ}$ and landing gear deployed showing the effects of amplitude and frequency scaling.

magnitude. At $500 \mathrm{~Hz}$ the main and nose landing gear are primary sources with the gear cavity and perhaps the inboard flap contributing. Sources are also evident around the engine outlet, which is outfitted with a hush kit. Two sources can also be seen on the engine nacelle downstream of the gear. Various holes on the nacelle are used to allow airflow into or out of the engines, and they are often noise sources. In this case, they are relatively weak. At $1000 \mathrm{~Hz}$, a loud tone is generated on the main landing gear. A small cavity is located on the knee of the landing gear, and numerical simulations[18] and wind tunnel tests[19] were able to identify the source. The cavity resonance is sensitive to geometric details and cross flow, and often will only appear on one of the gear. At $1600 \mathrm{~Hz}$, the sources on the nacelles become more prominent and two weaker sources appear at the leading edges of the wings. Although these sources appear weak, they are relatively strong in narrow band $(37.5 \mathrm{~Hz})$ maps. The wide width $(1413-1778 \mathrm{~Hz})$ of the $1 / 3$ octave band somewhat masks the importance of the tone. The source is caused by scattering of fan tones off the leading edge of the wing. The primary fan tones are at 1600,2100 , and $3200 \mathrm{~Hz}$, and all of these have been clearly seen in narrow band maps for locations where the aircraft is approaching the array. The wings integration region was drawn to exclude this source in the array integrated spectra being used to isolate airframe noise. At $3150 \mathrm{~Hz}$, vents on the nacelle associated with DC generator cooling become dominant. 
At $5000 \mathrm{~Hz}$, the gear sources are commensurate with the vents, but the engine vents become completely dominant at 6300 $\mathrm{Hz}$ and above. Conspicuously absent in all the maps are sources around the flap edges, indicating the ACTE flap is a relatively quiet high-lift device. Additional details on the noise sources and noise reduction devices can be found in [5].

A comparison of the maps in Figs. 18 and 19 reveals that they are remarkably similar at all frequencies. The fuel vapor sources at $200 \mathrm{~Hz}$ are weaker in Fig. 18 but that source is known to vary from pass to pass. Every source is still identified on the poor atmospheric day, and even the relative strengths of the sources at each frequency matches that observed on the good atmospheric day. However, the $1 / 3$ octave band maps do mask some differences that can be seen in narrow band maps. In particular, at high frequencies, the maps on poor atmospheric days are more likely to look speckled (more sidelobes) because the signals from the aircraft have been attenuated to near the background levels. Furthermore, the problem is exacerbated on windy days when self noise on the microphones increases background levels. In this case, the day with better temperature and relative humidity was much more windy.

Beamform maps from 2017 are shown in Figs. 20 (best weather conditions on 100317) and 21 (worst conditions on 101117). Again, the maps are very similar from the two days despite very different atmospheric conditions. However, differences can be observed between the two years by comparing Figs. 18 and 20 or 19 and 21. The primary difference is seen to be the weakening in 2017 of the sources at the vents for DC generator cooling. To facilitate the isolation of the airframe noise sources, the DC generators were turned off in 2017 while the aircraft was close to the array. Hence, in 2017, the landing gear and engine outlet sources are much more prominent in the maps at $5000 \mathrm{~Hz}$ and above.

The 804 integrated spectra from the wing region with different corrections for absorption are shown in Fig. 22. (a) uncorrected, (b) ground corrected, (c) average corrected, and (d) layer corrected. All of these cases were processed with the same temperature (and, hence, speed of sound) in the beamforming process. For the uncorrected result, atmospheric absorption was not included. Clearly, flight test data collected on different days cannot be compared without accounting for atmospheric absorption. Atmospheric absorption corrections were applied to each of the 29 time blocks used to obtain the average beamform map for aircraft positions in the flight direction within $\pm 50 \mathrm{ft}(15 \mathrm{~m})$ of the array. The ground corrected result was adjusted using observations from two ground based weather towers. Although the collapse is significantly improved, the spread in the data is still large. The average corrected data used a single layer with the average of the meteorological measurements from 0 to $400 \mathrm{ft}(121.9 \mathrm{~m})$, whereas the layer corrected used the sum of the corrections over $25 \mathrm{ft}(7.6 \mathrm{~m})$ layers from the ground to height of the aircraft. Using an average correction or layers makes very little difference in the results, and both show a reasonable collapse. However, the spread is still several dB, and is even evident below $2 \mathrm{kHz}$ where absorption effects are relatively small. Furthermore, the passes on each day appear to be grouped together. Although the highest levels were observed on the best atmospheric day (102116), and the lowest on the worst (101117), the trend is not consistent. The differences underscore the difficulty in controlling all of the parameters relevant to noise generation and propagation when conducting flight tests. The discrepancies should not be solely attributed to problems with the absorption corrections. Other factors include scattering from atmospheric turbulence, wind gusts and microphone response drift.

Figure 23 examines the effect of the corrections on the data from a single pass on two different days. In (a) on 092116, the temperature was relatively uniform with altitude, so even the ground observations are a good approximation of the average conditions. Hence, all of the corrections produce similar results. However, in (b) on 101217, a strong temperature inversion was observed, and the ground observations are inadequate. Again, the average and layered corrections are within a dB. However, the aircraft is less than $400 \mathrm{ft}(122 \mathrm{~m})$ from the array for this analysis, and the differences would be exaggerated as the distance of propagation is increased to the extent used in certification microphone analyses.

The influence of the aircraft position is examined in Fig. 24 where an interval from -300 to $-200 \mathrm{ft}$ (-91 to $61 \mathrm{~m})$ is used. Not only is the distance to the microphones changing, the directivity of the landing gear source is manifesting itself. Clearly, the collapse of the data degrades as the distance between the array and the aircraft increases. In Fig. 24 (a) the discrepancies at $500 \mathrm{~Hz}$ are significant, so absorption alone is not a likely cause of the differences. Other propagation effects or an influence on the source itself could be involved. Nonetheless, if the passes on days with poor atmospheric conditions are excluded, the collapse is improved. Beyond $4 \mathrm{kHz}$, the data diverges into good and moderate atmospheric groups. Unfortunately, with only two good and two moderate atmospheric days, not enough data is available to make statistically meaningful conclusions. Having more passes from different days would be advantageous; however, most flight tests do not even collect as much data as is available from this campaign. Furthermore, the beamform maps showed that noise from the engines and vents becomes dominant above $4 \mathrm{kHz}$, so, even with the array integration, isolating the airframe sources in the wing region may not be possible depending on the conditions. 


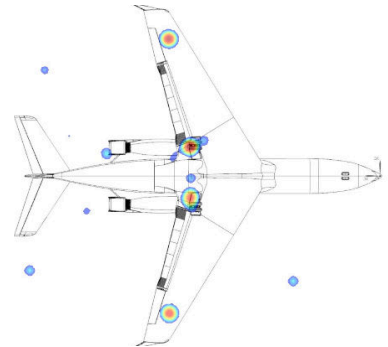

(a) $200 \mathrm{~Hz}$

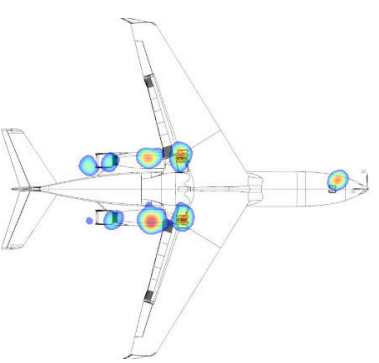

(e) $3150 \mathrm{~Hz}$

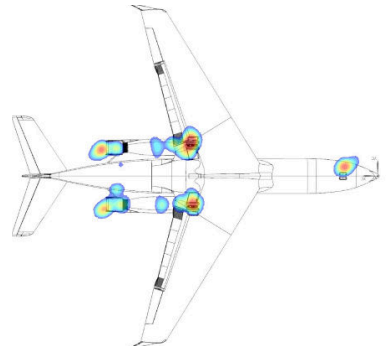

(b) $500 \mathrm{~Hz}$

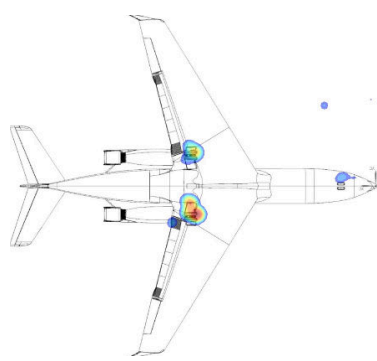

(c) $1000 \mathrm{~Hz}$

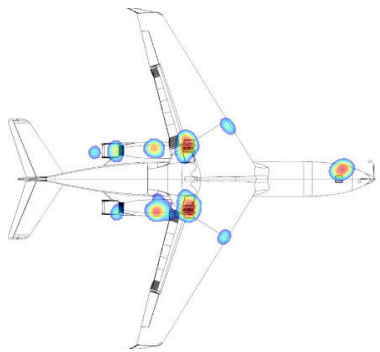

(d) $1600 \mathrm{~Hz}$

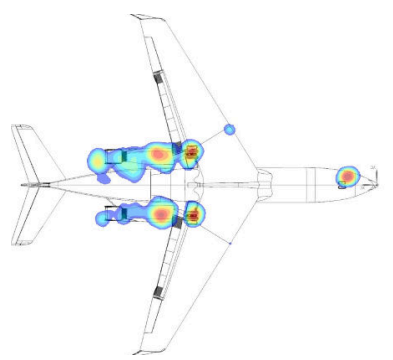

(f) $5000 \mathrm{~Hz}$

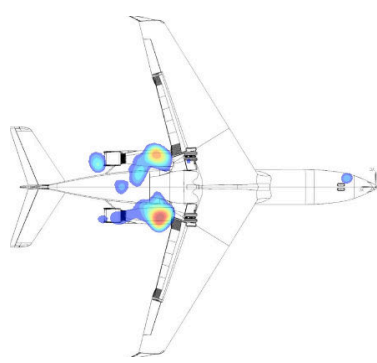

(g) $6300 \mathrm{~Hz}$

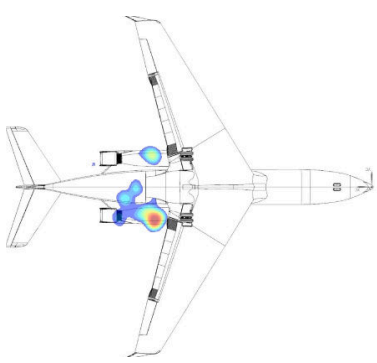

(h) $8000 \mathrm{~Hz}$

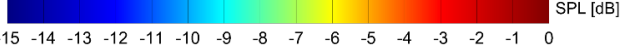

Fig. 18 1/3 octave beamform maps for 804 passes on 092116 with ACTE flaps at $25^{\circ}$ and landing gear deployed.

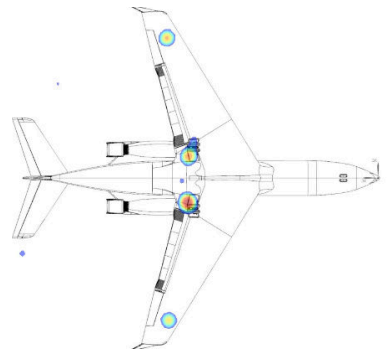

(a) $200 \mathrm{~Hz}$

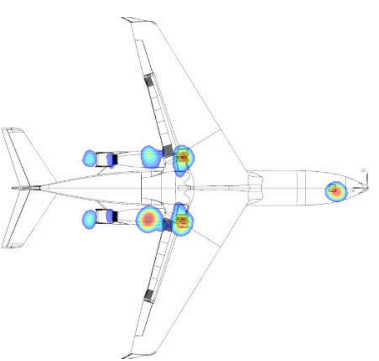

(e) $3150 \mathrm{~Hz}$

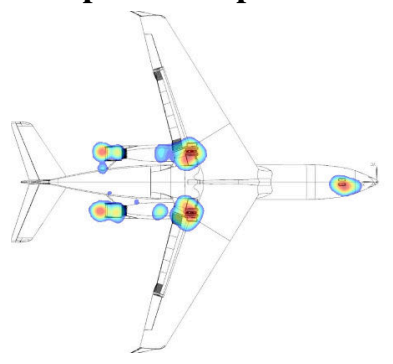

(b) $500 \mathrm{~Hz}$

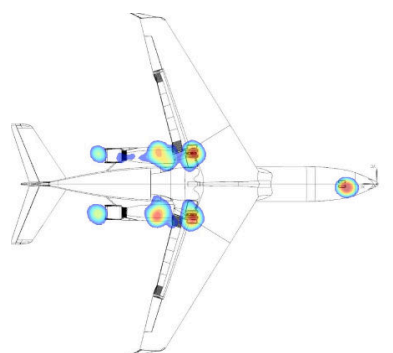

(f) $5000 \mathrm{~Hz}$

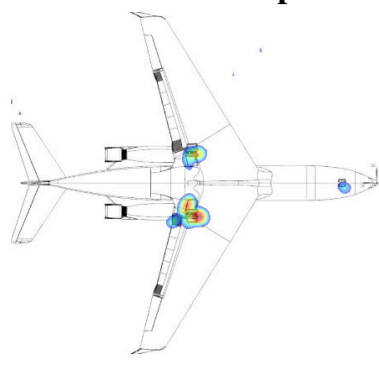

(c) $1000 \mathrm{~Hz}$

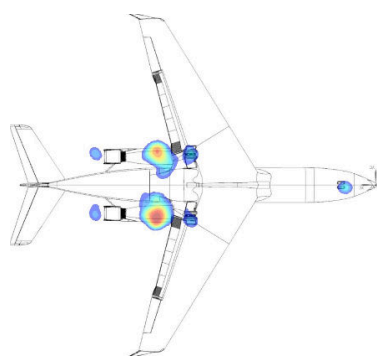

(g) $6300 \mathrm{~Hz}$

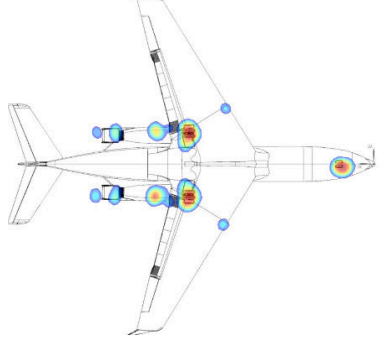

(d) $1600 \mathrm{~Hz}$

$$
\begin{array}{llllllllllllllll|}
\hline 15 & -14 & -13 & -12 & -11 & -10 & -9 & -8 & -7 & -6 & -5 & -4 & -3 & -2 & -1 & 0
\end{array}
$$

Fig. 19 1/3 octave beamform maps for 804 passes on 092716 with ACTE flaps at $25^{\circ}$ and landing gear deployed. 


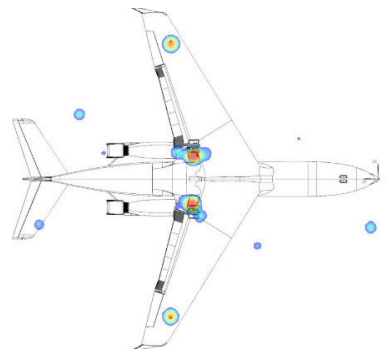

(a) $200 \mathrm{~Hz}$

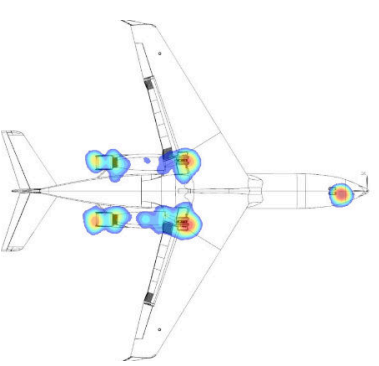

(e) $3150 \mathrm{~Hz}$

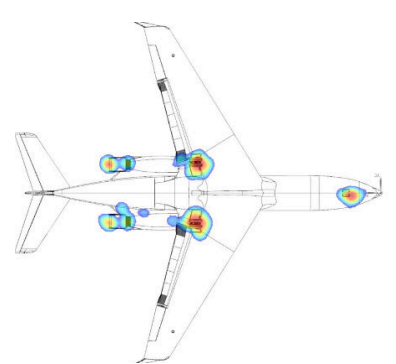

(b) $500 \mathrm{~Hz}$

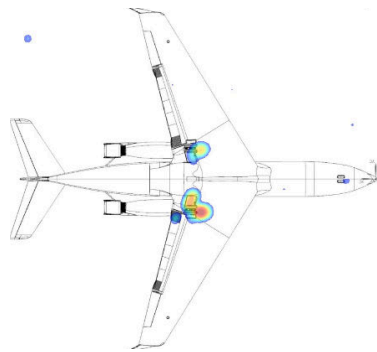

(c) $1000 \mathrm{~Hz}$

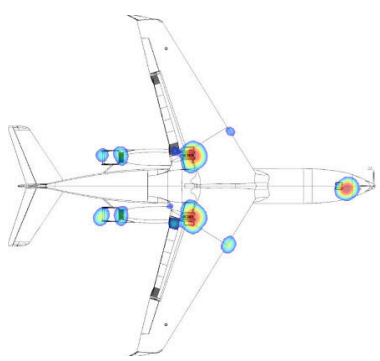

(d) $1600 \mathrm{~Hz}$

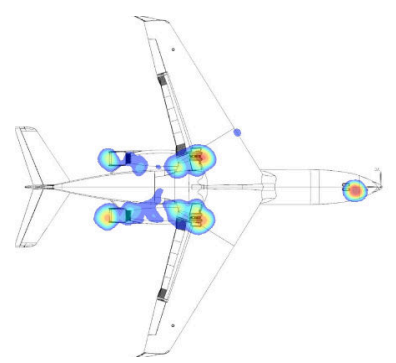

(f) $5000 \mathrm{~Hz}$

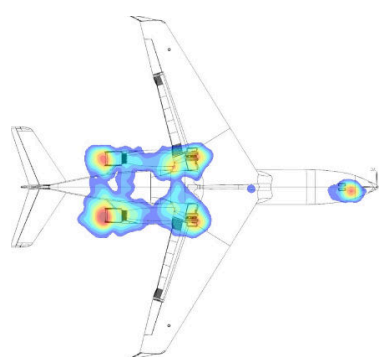

(g) $6300 \mathrm{~Hz}$

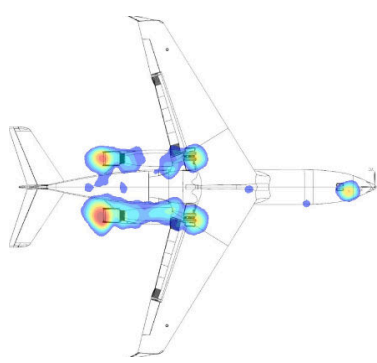

(h) $8000 \mathrm{~Hz}$

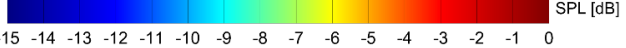

Fig. 20 1/3 octave beamform maps for 804 passes on 100317 with ACTE flaps at $25^{\circ}$ and landing gear deployed.

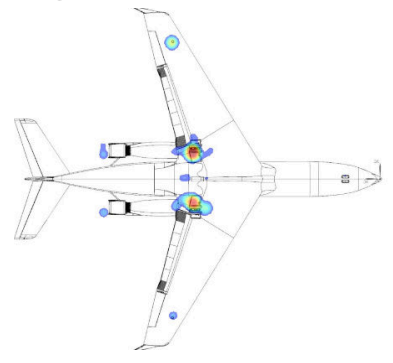

(a) $200 \mathrm{~Hz}$

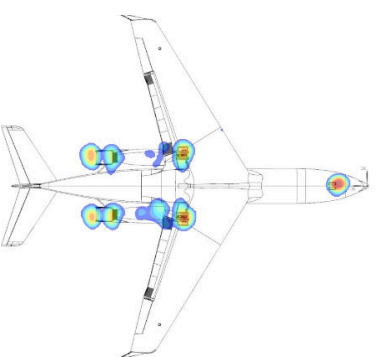

(e) $3150 \mathrm{~Hz}$

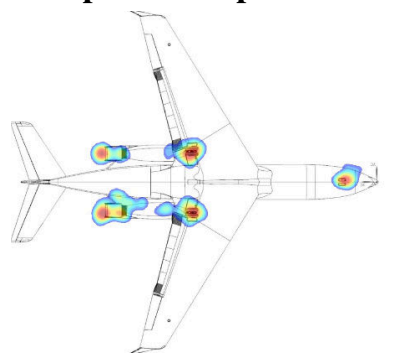

(b) $500 \mathrm{~Hz}$

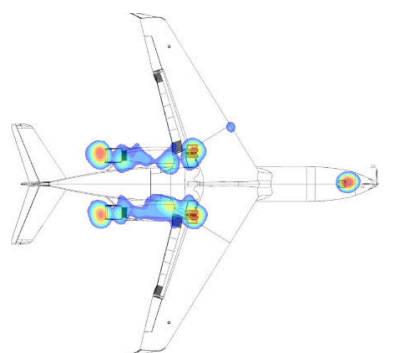

(f) $5000 \mathrm{~Hz}$

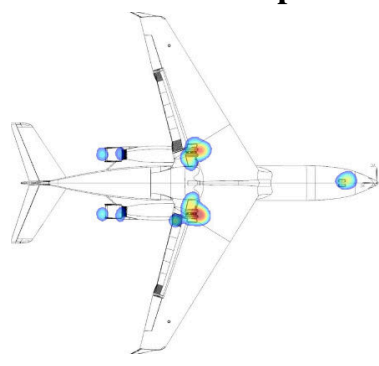

(c) $1000 \mathrm{~Hz}$

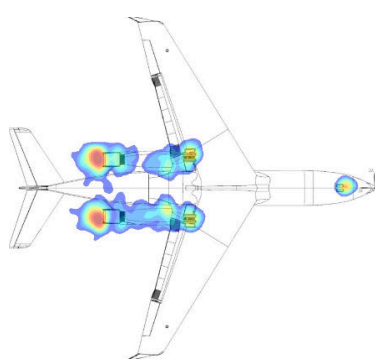

(g) $6300 \mathrm{~Hz}$

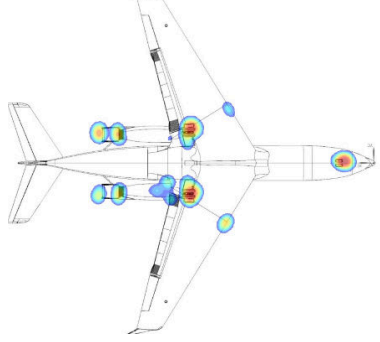

(d) $1600 \mathrm{~Hz}$

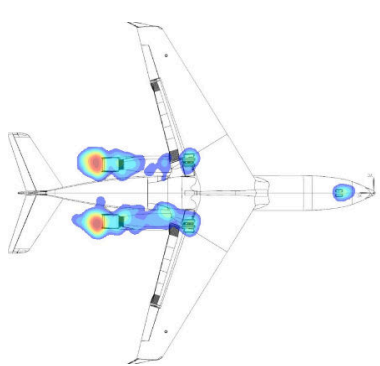

(h) $8000 \mathrm{~Hz}$ \begin{tabular}{|lllllllllllllllll}
\hline 15 & -14 & -13 & -12 & -11 & -10 & -9 & -8 & -7 & -6 & -5 & -4 & -3 & -2 & -1 & 0 &
\end{tabular}

Fig. 21 1/3 octave beamform maps for 804 passes on 101117 with ACTE flaps at $25^{\circ}$ and landing gear deployed. 


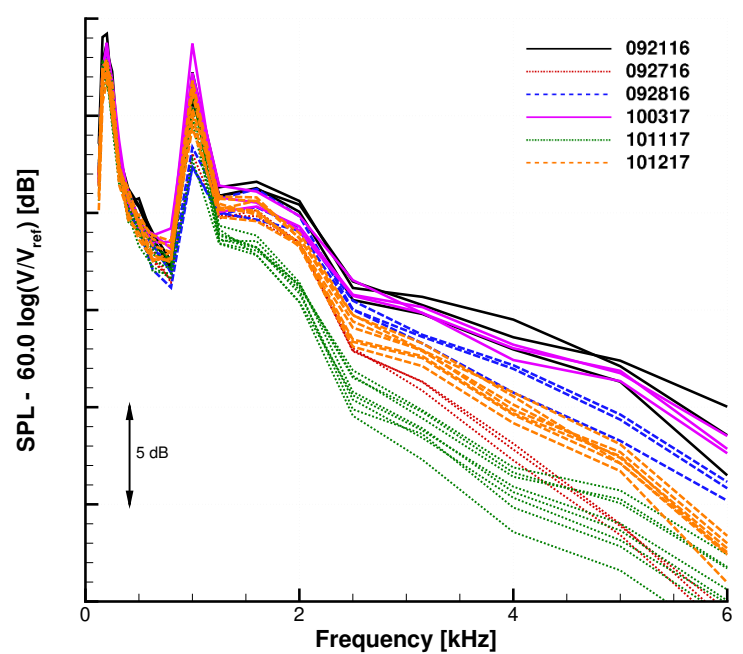

(a) Uncorrected

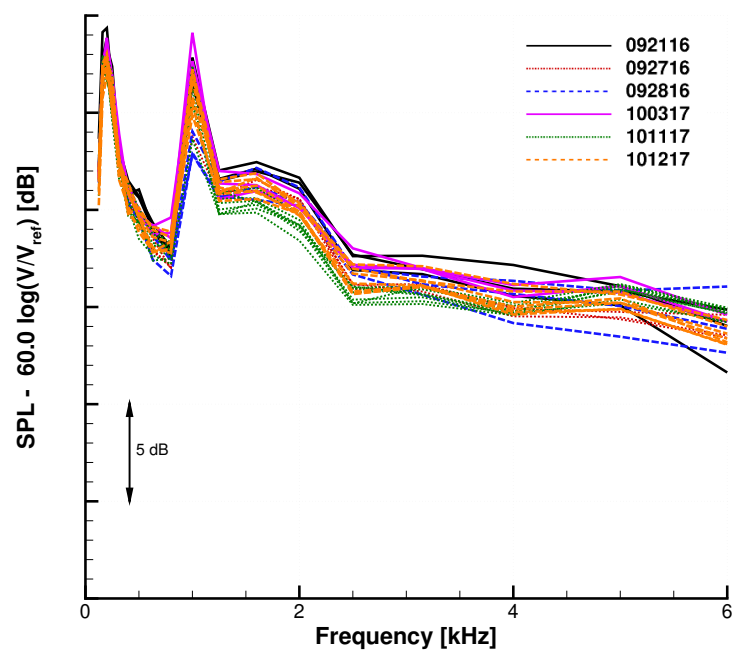

(c) Average corrected

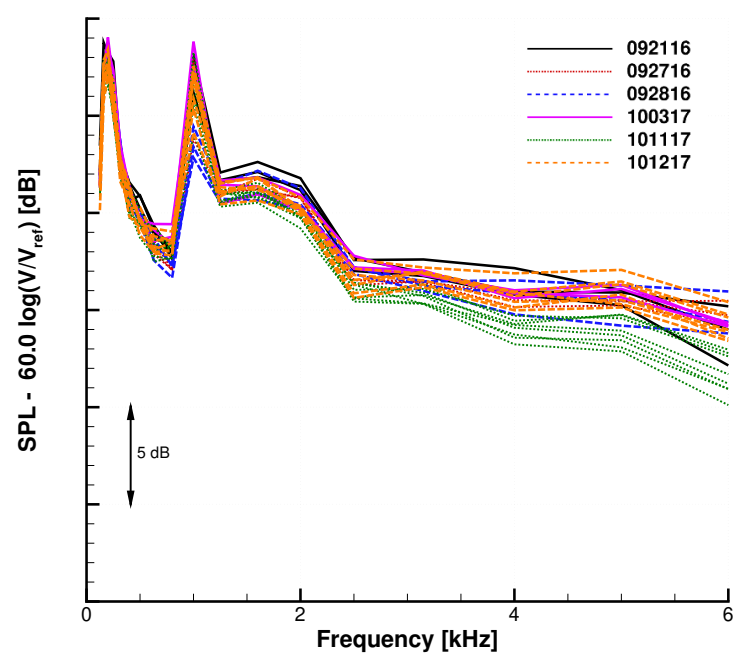

(b) Ground corrected

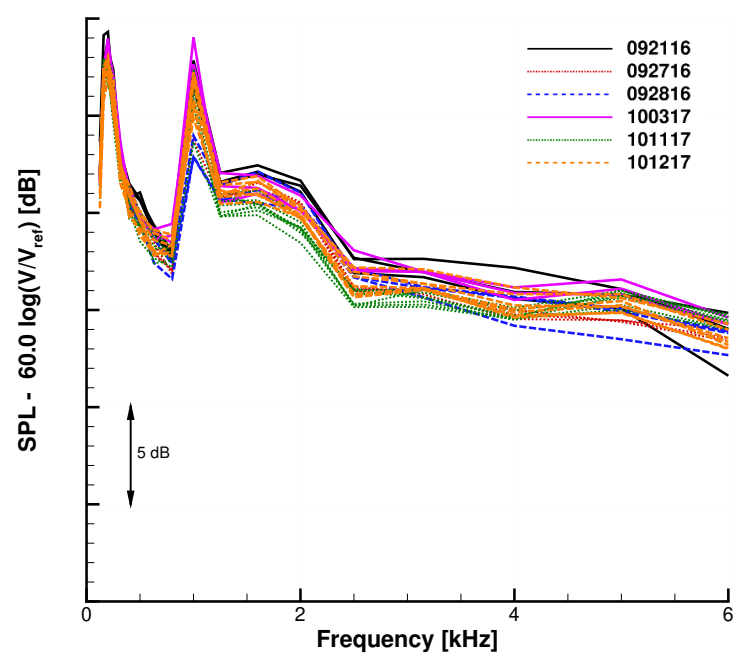

(d) Layer Corrected

Fig. $221 / 3$ octave integrated spectra from the wing region for 804 passes with ACTE flaps at $25^{\circ}$ and landing gear deployed. 


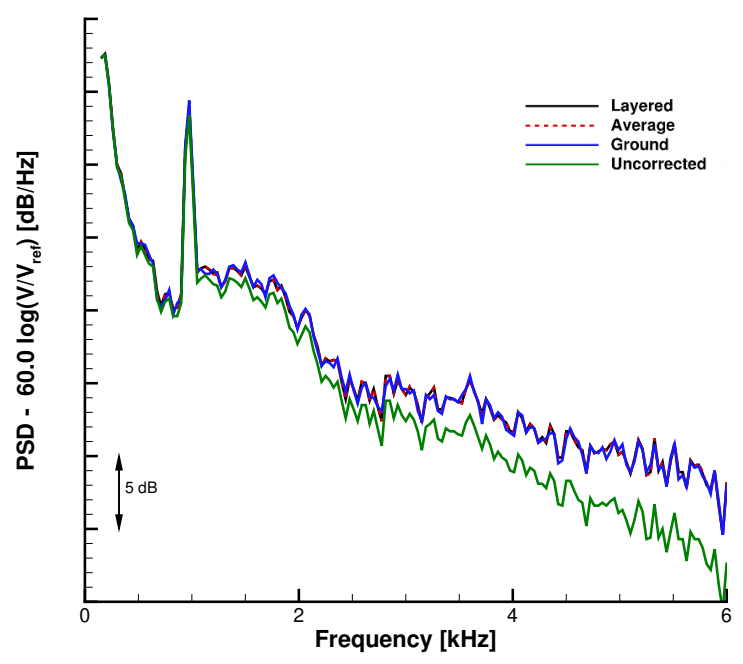

(a) 092116

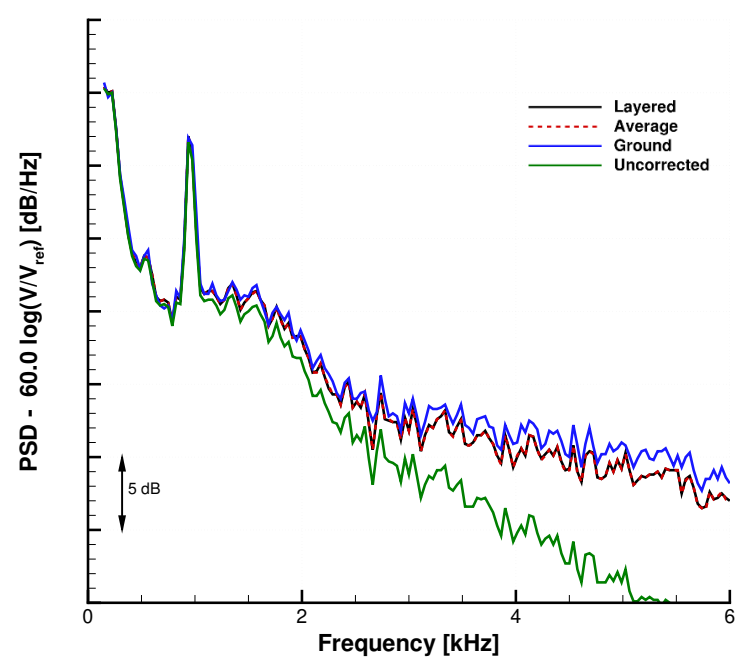

(b) 101217

Fig. 23 Integrated spectra on two days showing the effect of different atmospheric measurements on the absorption correction for 804 passes with ACTE flaps at $25^{\circ}$ and landing gear deployed.

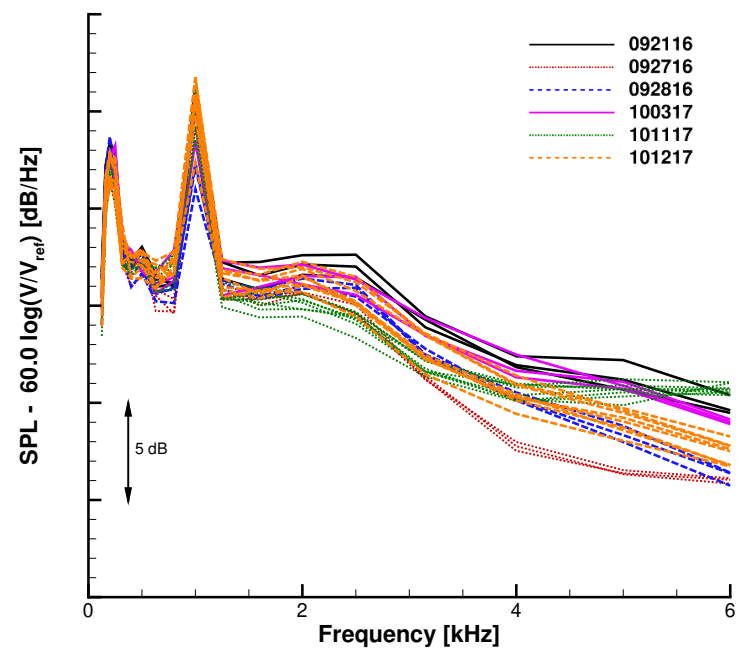

(a) All passes

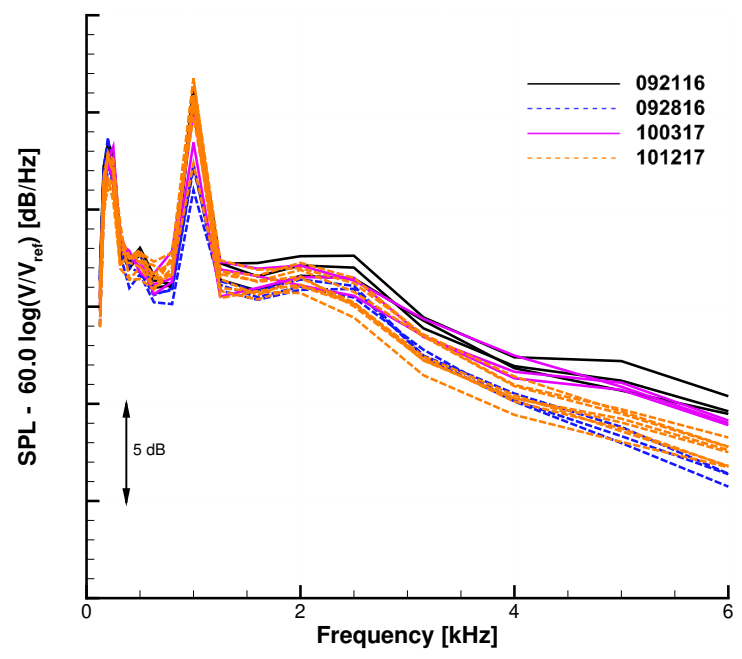

(b) Passes on days within limits

Fig. 24 1/3 octave integrated spectra from the wing region for 804 passes with ACTE flaps at $25^{\circ}$ and landing gear deployed. Spectra obtained with an aircraft position of -300 to $-200 \mathrm{ft}(-91$ to $61 \mathrm{~m})$ relative to the center of the array. 
To further examine the ability to collapse array data, all 808 passes with the Fowler flaps at $20^{\circ}$ and the landing gear deployed are examined. Fig. 25 (a) shows the temperature-relative humidity measurements from the six days with 808 flights. Just as for the 804 flights, there are two good, two moderate, and two poor atmospheric days. The ground wind magnitude is shown in Fig. 25](b), which generally indicates that the winds were within the $10 \mathrm{kn}$ limit. On 081017, flights were delayed until the winds died down sufficiently. The first pass of interest was at 45,000 seconds.

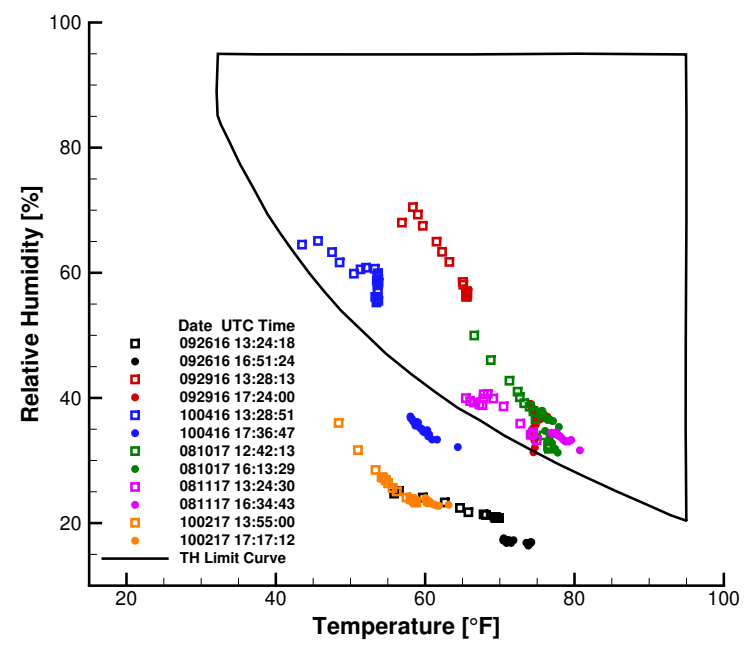

(a) Temperature-Relative Humidity

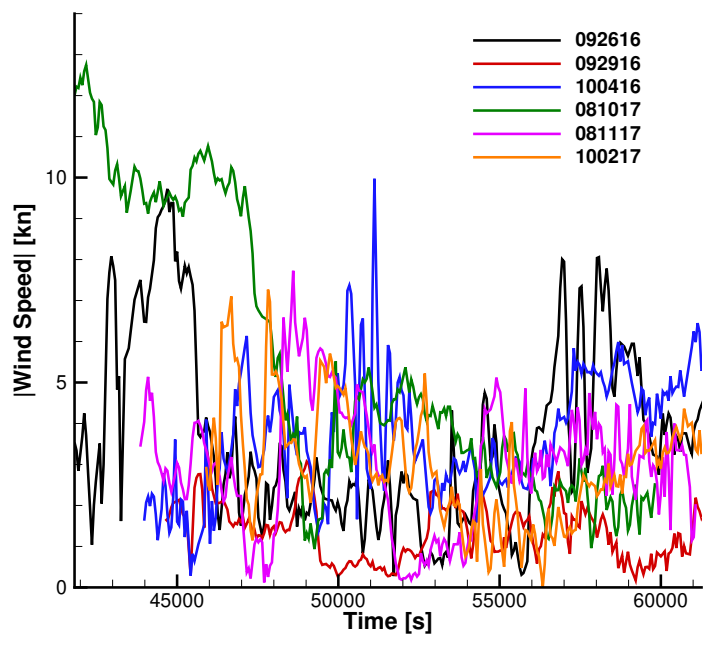

(b) Surface Wind Speed

Fig. 25 Atmospheric observations from all of the days with 808 passes with flaps at $20^{\circ}$ and landing gear deployed.

Beamform maps from the best (092916) and worst (092616) meteorological days for 808 passes in 2016 are compared in Figs. 26 and 27. At $200 \mathrm{~Hz}$, similar to the maps for 804, the fuel vapor vents and landing gear cavities are the strongest sources. At $500 \mathrm{~Hz}$, the landing gear is the primary source, but the inboard flap edges now extend the source region relative to 804. Furthermore, weaker sources on brackets and the outboard flap edges can bee seen. At $1 \mathrm{kHz}$, the landing gear tone is dominant, but the flap edges and brackets are visible at all higher frequencies. Above $5 \mathrm{kHz}$, the noise from vents on the nacelle are not significant as with the 804 aircraft. The 808 aircraft does not have an DC generator; hence, DC generator cooling source is absent on 808. Furthermore, the source at the engine outlet is weaker than that of the gear for all frequencies. Even though the engines on the two aircraft were thought to be identical, there are still subtle differences. They were both operated at ground-idle conditions, but produced different noise signatures.

The comparison of the results from the two different days reveals that the maps are very similar up to $5 \mathrm{kHz}$, but at higher frequencies the maps on 092616 become speckled with random sources. The aircraft altitudes for the 092916 and 092616 passes were within $30 \mathrm{ft}$ of each other, so the distance from the array to the aircraft was similar for the two. The breakdown arises because the array can no longer sufficiently reject the background signal to identify the true aircraft. An increase in background levels, possibly associated with wind generated self noise, decorrelation effects[20] caused by atmospheric turbulence, and strong atmospheric absorption all are likely contributors to the breakdown in the processing. A similar comparison of the beamform maps from the best (081017) and worst (100217) days from 2017 shown in Figs. 28 and 29 does not indicate any breakdown in the processing. In this case, the maps appear very similar across all frequencies between the two days.

Now considering the integrated spectra obtained from the beamform maps, Fig. 30 (a) and (b) compare the effect of velocity scaling on the amplitude for an overhead aircraft position. The collapse is better with the scaling, but a spread of 5 $\mathrm{dB}$ is still observed at some frequencies. The 808 aircraft is not equipped with the instrumentation available on 804 , so the velocities were obtained from pilot callouts of the indicated air speed, rather than the true air speed, as the aircraft passed over the array. Furthermore, parameters such as the aircraft angle of attack and roll, pitch, and yaw could not be monitored and may be significantly different between passes. For more upstream aircraft positions, the discrepancies between the passes increases as Fig 30 (c) indicates. Restricting the comparison to only those days with temperature-relative humidity within the recommended limits considerably tightens the spread in the curves. The passes on 100416 are excluded because they were obtained towards the end of the day after the conditions deteriorated. The remaining curves are quite similar except around $2 \mathrm{kHz}$ where the passes on 081117 are lower. Beamform maps for the upstream aircraft position from 081017 and 081117 are shown in Figs. 31 and 32 The maps look similar up to $3150 \mathrm{~Hz}$, but at $5 \mathrm{kHz}$, the maps on 100217 begin to look distorted. Even though the atmospheric conditions on 100217 were within the recommended limits, the array had difficulties resolving the aircraft signal at high frequency. Nonetheless, the integrated values are still similar for the two 


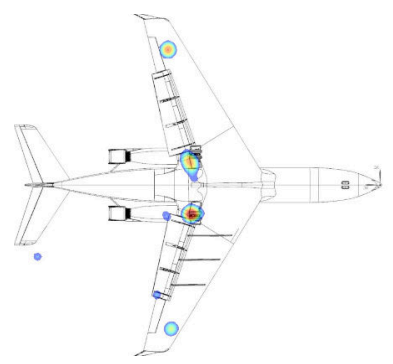

(a) $200 \mathrm{~Hz}$

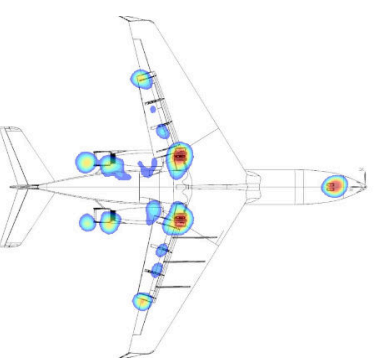

(e) $3150 \mathrm{~Hz}$

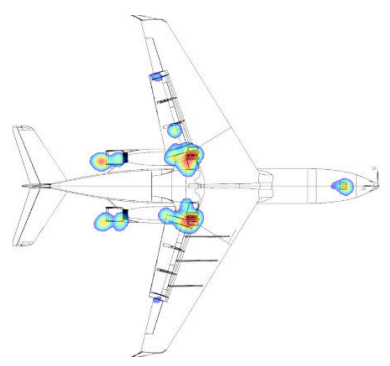

(b) $500 \mathrm{~Hz}$

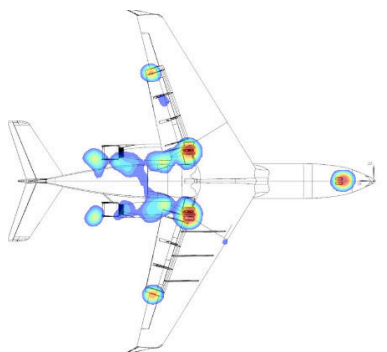

(f) $5000 \mathrm{~Hz}$

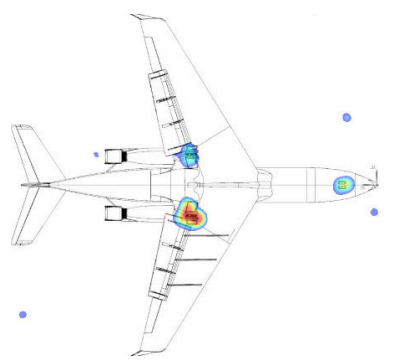

(c) $1000 \mathrm{~Hz}$

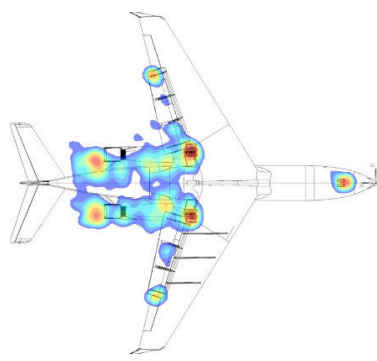

(g) $6300 \mathrm{~Hz}$

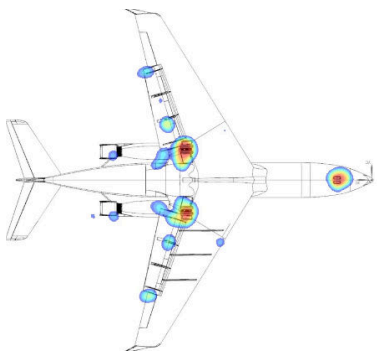

(d) $1600 \mathrm{~Hz}$

\begin{tabular}{llllllllllllllll|}
\hline-15 & -14 & -13 & -12 & -11 & -10 & -9 & -8 & -7 & -6 & -5 & -4 & -3 & -2 & -1 & 0
\end{tabular}

Fig. $261 / 3$ octave beamform maps for 808 passes on 092916 with Fowler flaps at $20^{\circ}$ and landing gear deployed.

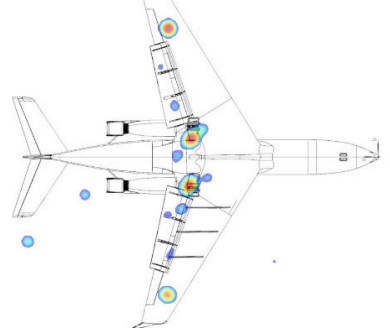

(a) $200 \mathrm{~Hz}$

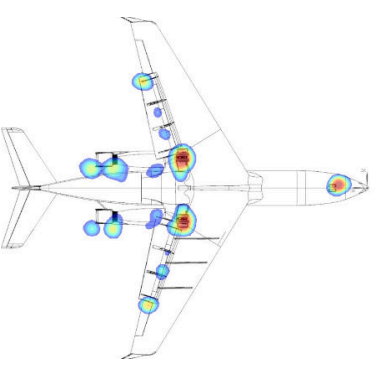

(e) $3150 \mathrm{~Hz}$

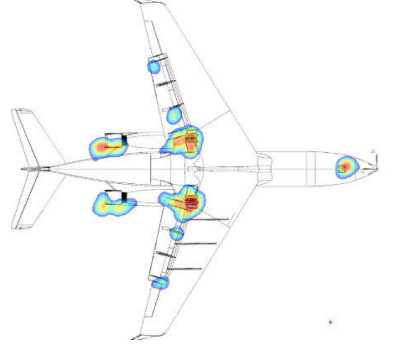

(b) $500 \mathrm{~Hz}$

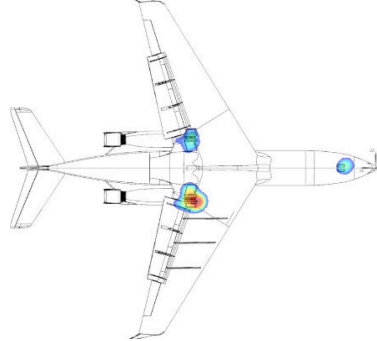

(c) $1000 \mathrm{~Hz}$

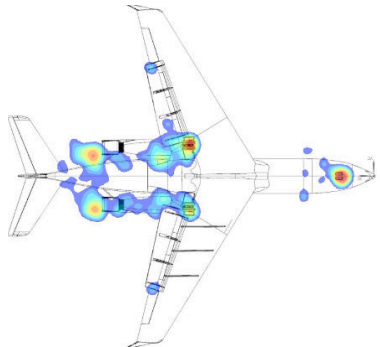

(h) $8000 \mathrm{~Hz}$

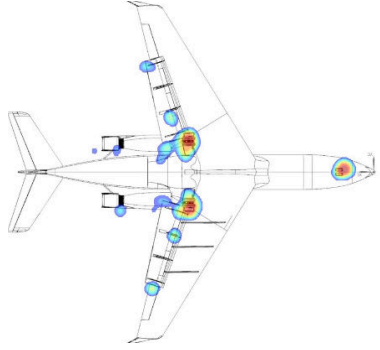

(d) $1600 \mathrm{~Hz}$

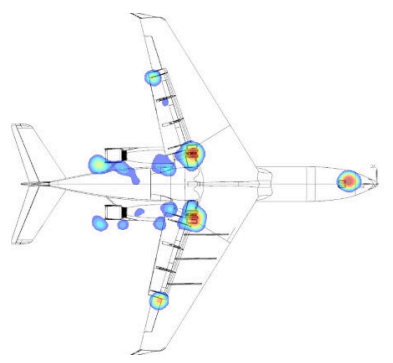

(f) $5000 \mathrm{~Hz}$

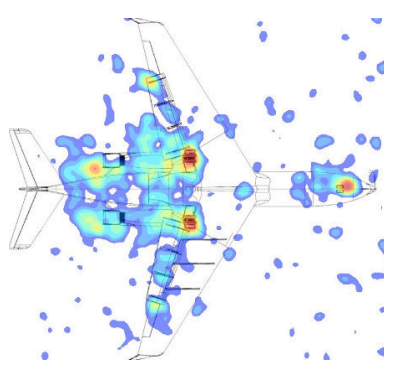

(g) $6300 \mathrm{~Hz}$

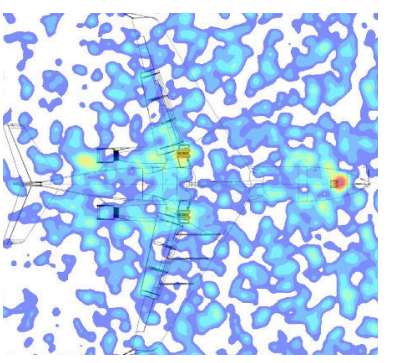

(h) $8000 \mathrm{~Hz}$

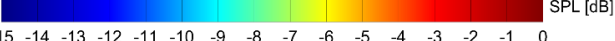

Fig. 27 1/3 octave beamform maps for 808 passes on 092616 with Fowler flaps at $20^{\circ}$ and landing gear deployed.

days. The maps also show that the flap edge and bracket sources are strong radiators in the forward direction. Indeed, all of the airframe noise sources tend to be louder in the forward arc as a comparison of Figs 30 (b) and (d) indicates.

The array integrated spectra can exhibit significant differences across days, but similar differences can also be seen in the individual microphone data. To facilitate such a comparison, the average of all 185 microphone spectra are compared for the 804 flights in Fig. 33 (a) and for all the 808 passes in Fig. 33 (b). The aircraft position is -300 to $-200 \mathrm{ft}$ (-91 to -61 $\mathrm{m}$ ) where the discrepancies are more apparent. The narrow band spectra (with a $37.5 \mathrm{~Hz}$ bin width, presented as PSD) show a similar grouping to that observed with the array integrated spectra. The differences are in the raw data, but a drift in the microphone response is unlikely. A health monitoring system[2] was used to track day-to-day changes in the microphone 


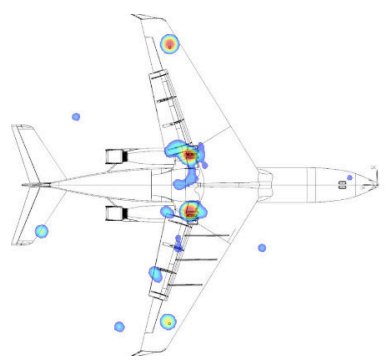

(a) $200 \mathrm{~Hz}$

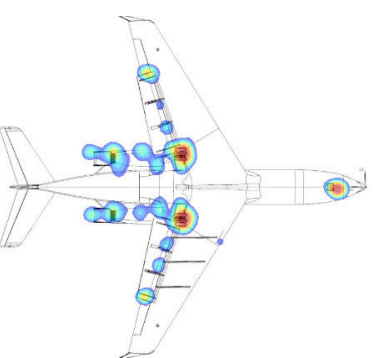

(e) $3150 \mathrm{~Hz}$

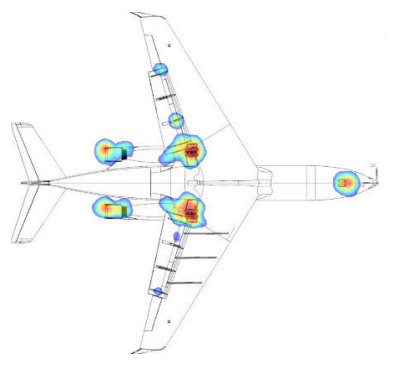

(b) $500 \mathrm{~Hz}$

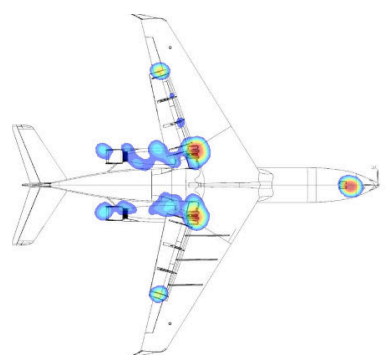

(f) $5000 \mathrm{~Hz}$

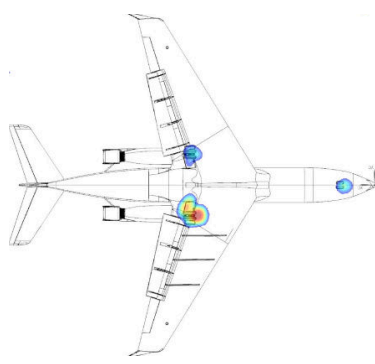

(c) $1000 \mathrm{~Hz}$

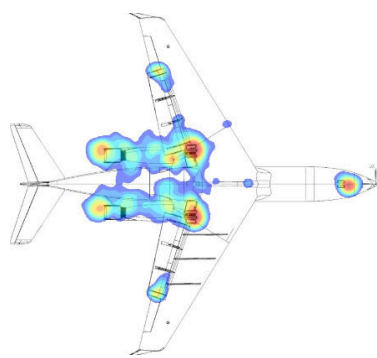

(g) $6300 \mathrm{~Hz}$

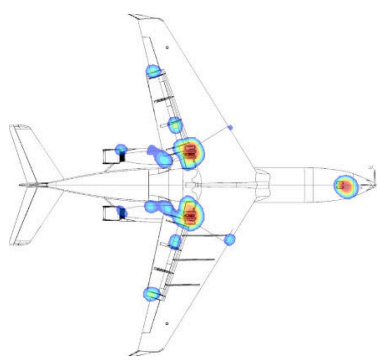

(d) $1600 \mathrm{~Hz}$

\begin{tabular}{llllllllllllllll|}
\hline-15 & -14 & -13 & -12 & -11 & -10 & -9 & -8 & -7 & -6 & -5 & -4 & -3 & -2 & -1 & 0
\end{tabular}

Fig. $281 / 3$ octave beamform maps for 808 passes on 081017 with Fowler flaps at $20^{\circ}$ and landing gear deployed.

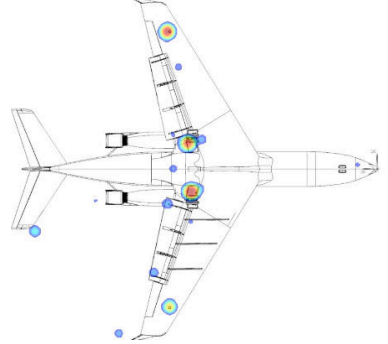

(a) $200 \mathrm{~Hz}$

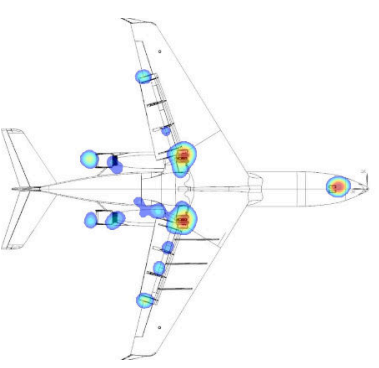

(e) $3150 \mathrm{~Hz}$

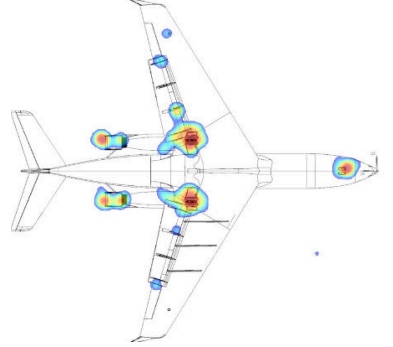

(b) $500 \mathrm{~Hz}$

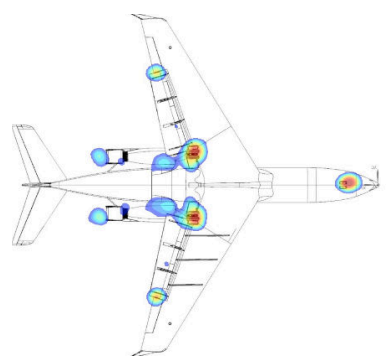

(f) $5000 \mathrm{~Hz}$

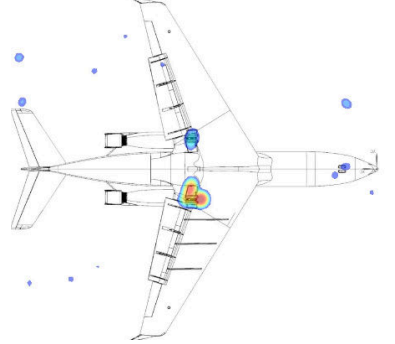

(c) $1000 \mathrm{~Hz}$

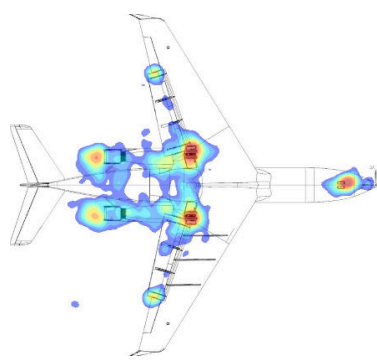

(g) $6300 \mathrm{~Hz}$

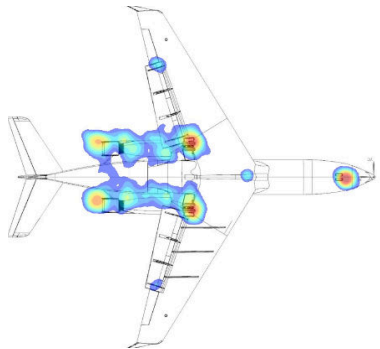

(h) $8000 \mathrm{~Hz}$

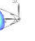

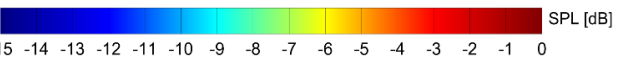

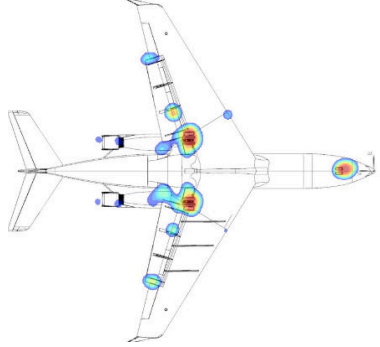

(d) $1600 \mathrm{~Hz}$

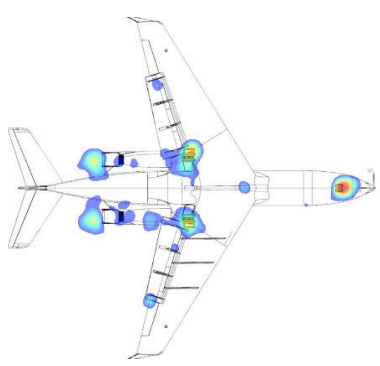

(h) $8000 \mathrm{~Hz}$

Fig. $291 / 3$ octave beamform maps for 808 passes on 100217 with Fowler flaps at $20^{\circ}$ and landing gear deployed.

responses, and only small differences were observed. Furthermore, several Bruel and Kjaer 1/4" microphones were used to make certification type measurements, and they also indicated similar trends. These microphones were calibrated before and after flights on each day, so sensitivities were tracked and found to be consistent throughout the testing period.

\section{Conclusions}

The incorporation of local meteorological conditions into acoustic flight tests data is essential to properly characterize aircraft noise. For microphone array processing, the meteorological conditions influence the speed of sound used in 


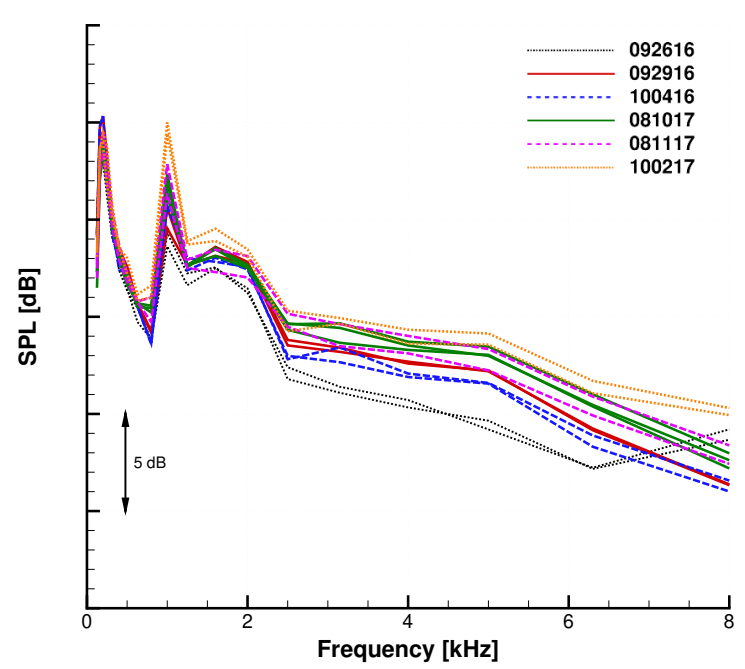

(a) -50 to $50 \mathrm{ft}$ (-15 to $15 \mathrm{~m})$, unscaled

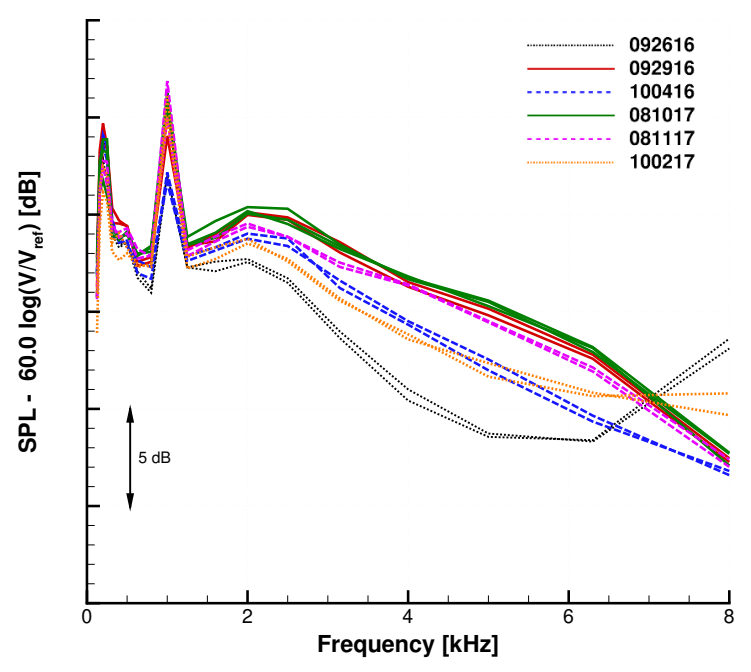

(c) -300 to $-200 \mathrm{ft}$ (-91 to $-61 \mathrm{~m})$, all passes

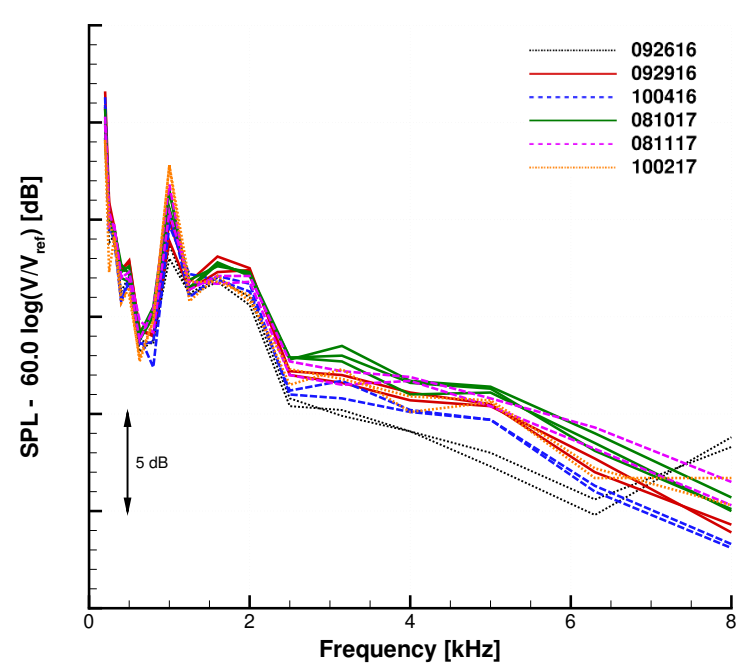

(b) -50 to $50 \mathrm{ft}$ ( 15 to $15 \mathrm{~m})$

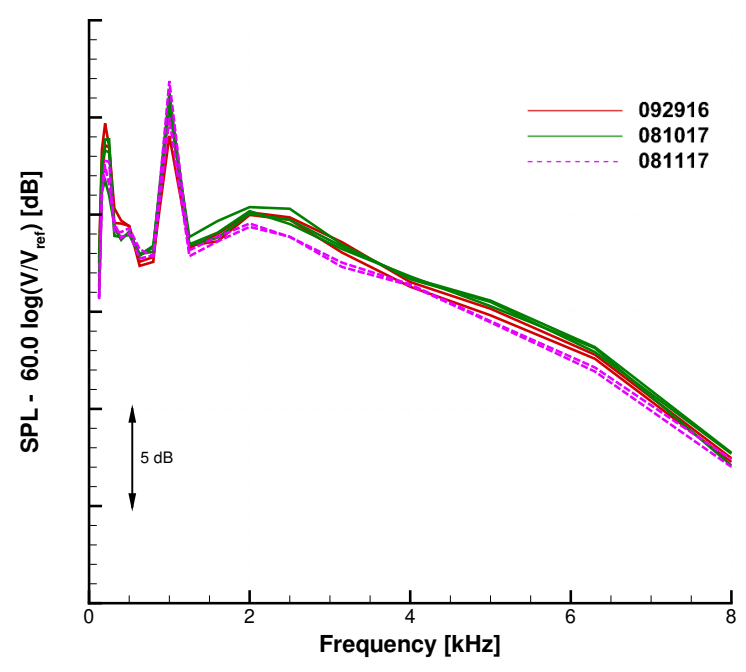

(d) -300 to $-200 \mathrm{ft}$ (-91 to $-61 \mathrm{~m}$ ), passes on days within limits

Fig. $30 \quad 1 / 3$ octave integrated spectra using different aircraft positions relative to the center of the array. 808 passes with standard Fowler flaps at $20^{\circ}$ and landing gear deployed. Wing region used in integration of CLEAN beamform maps. Layered corrections applied.

beamforming and also atmospheric absorption corrections. Processing data with the average temperature, relative humidity, and pressure between the aircraft and ground produced similar results to breaking the atmosphere into $25 \mathrm{ft}(7.6 \mathrm{~m})$ layers and applying the corrections within each layer. The observed differences were a fraction of a $\mathrm{dB}$ when the aircraft position relative to the array was around $400 \mathrm{ft}(122 \mathrm{~m})$. Microphone arrays generally do not work well when the source is far from overhead of the array, so they are generally used when the distance between the aircraft and microphones is relatively small compared with what is typically used in single microphone measurements. The layered approach will produce appreciably different results for certification type measurements.

The use of atmospheric observations made within $30 \mathrm{ft}(10 \mathrm{~m})$ of the ground was found to be adequate only when the temperature variation with altitude is less than $5^{\circ} \mathrm{F}\left(2.8^{\circ} \mathrm{C}\right)$. However, one cannot know that such a condition exists without actually measuring the profile.

Microphone array beamform maps were found to show similar distributions of sources regardless of the atmospheric conditions, but the amplitudes were much more sensitive. Furthermore, maps at frequencies above $4 \mathrm{kHz}$ were sometimes degraded because of some combination of high background noise levels, atmospheric absorption, and decorrelation caused by atmospheric turbulence.

The best collapse of array integrated spectra from aircraft flyovers was obtained by isolating the noise from the wings 


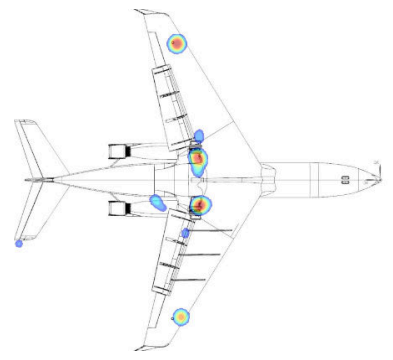

(a) $200 \mathrm{~Hz}$

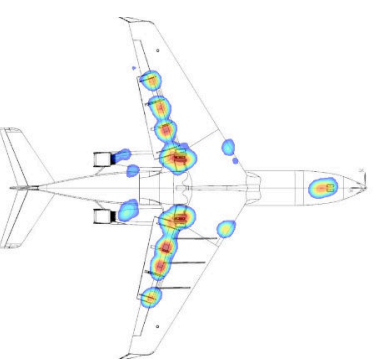

(e) $3150 \mathrm{~Hz}$

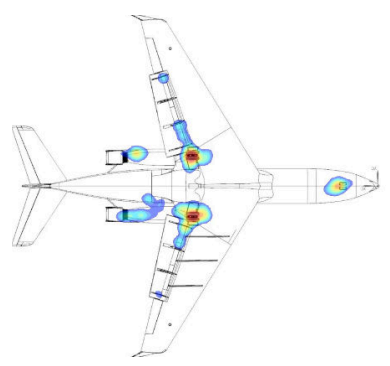

(b) $500 \mathrm{~Hz}$

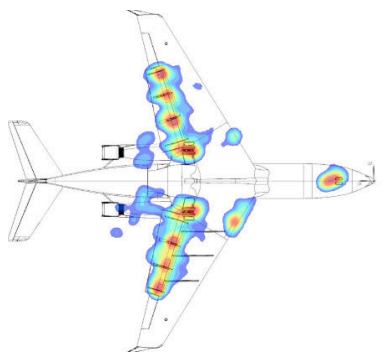

(f) $5000 \mathrm{~Hz}$

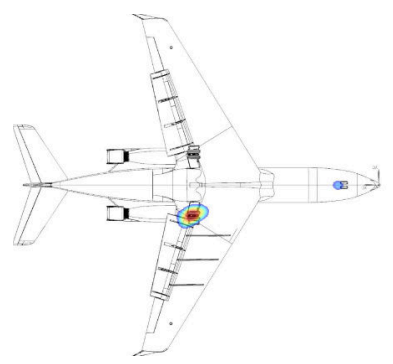

(c) $1000 \mathrm{~Hz}$

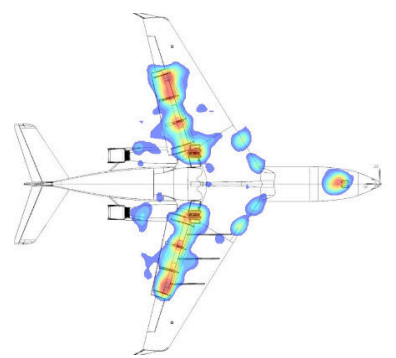

(g) $6300 \mathrm{~Hz}$

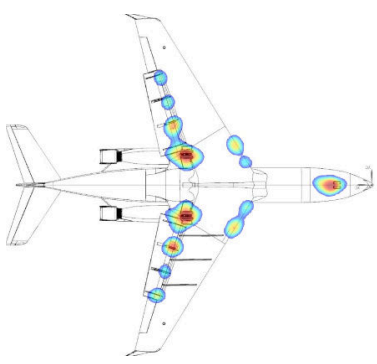

(d) $1600 \mathrm{~Hz}$

\begin{tabular}{lllllllllllllll|l}
\hline-15 & -14 & -13 & -12 & -11 & -10 & -9 & -8 & -7 & -6 & -5 & -4 & -3 & -2 & -1 & 0
\end{tabular}

Fig. 31 1/3 octave beamform maps for 808 passes on 081017 with Fowler flaps at $20^{\circ}$ and landing gear deployed.Aircraft located between -300 to $-200 \mathrm{ft}(-91$ to $-61 \mathrm{~m})$.

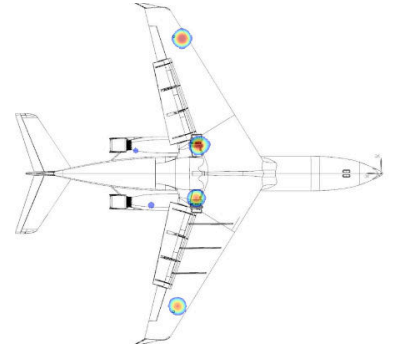

(a) $200 \mathrm{~Hz}$

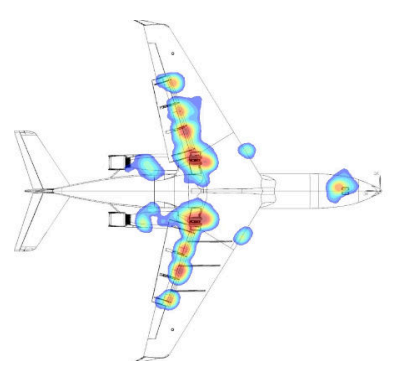

(e) $3150 \mathrm{~Hz}$

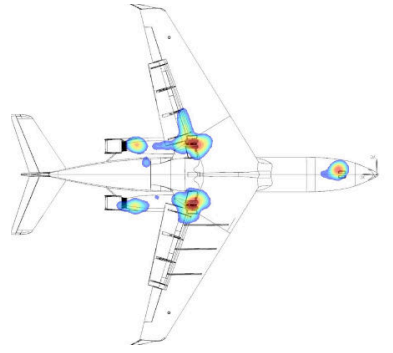

(b) $500 \mathrm{~Hz}$

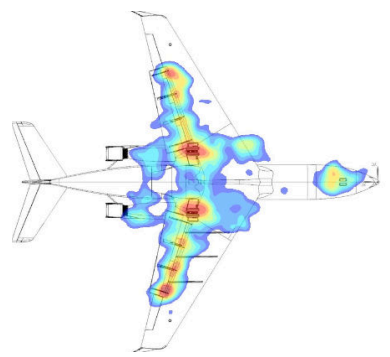

(f) $5000 \mathrm{~Hz}$

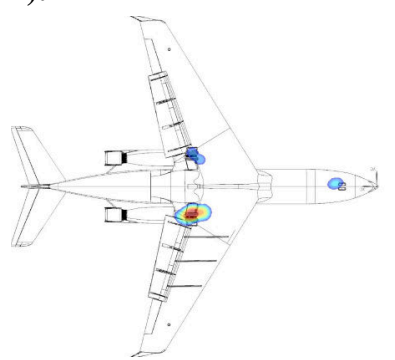

(c) $1000 \mathrm{~Hz}$

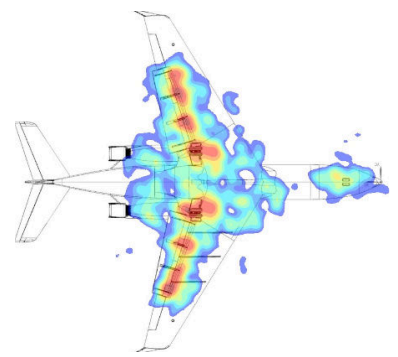

(g) $6300 \mathrm{~Hz}$

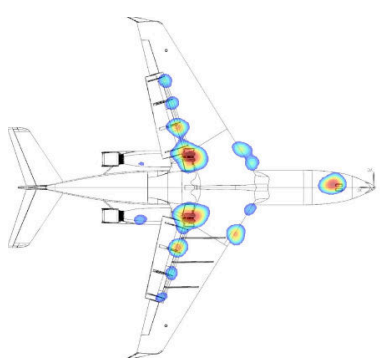

(d) $1600 \mathrm{~Hz}$

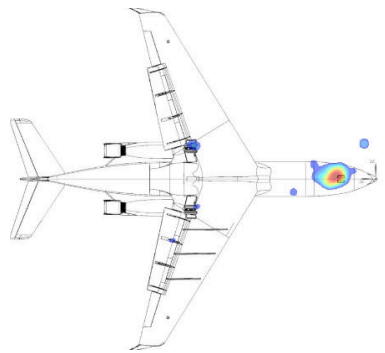

(h) $8000 \mathrm{~Hz}$

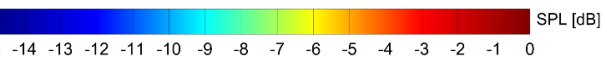

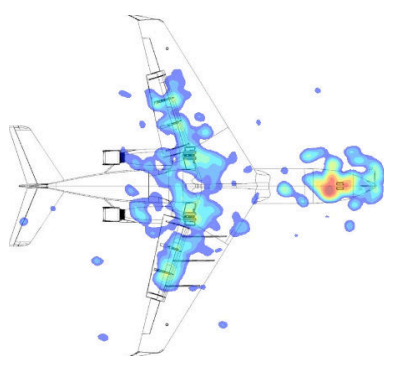

(h) $8000 \mathrm{~Hz}$

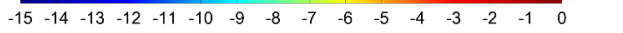

Fig. 32 1/3 octave beamform maps for 808 passes on 081117 with Fowler flaps at $20^{\circ}$ and landing gear deployed. Aircraft located between -300 to $-200 \mathrm{ft}$ (-91 to $-61 \mathrm{~m})$.

and main landing gear, adjusting the amplitude for the speed, and restricting the analysis to nearly overhead aircraft positions. Even for this case, differences of several dB were observed. Much larger differences were observed for aircraft positions approaching the array. These discrepancies are most likely a consequence of the complexity of flight testing rather than merely a shortcoming of the atmospheric measurements or absorption corrections. However, testing on days with atmospheric conditions within the limits proposed by McCollough and True[7] seems to significantly reduce the variability in the measured noise data. The best practice is to test on multiple days within the temperature-relative humidity 


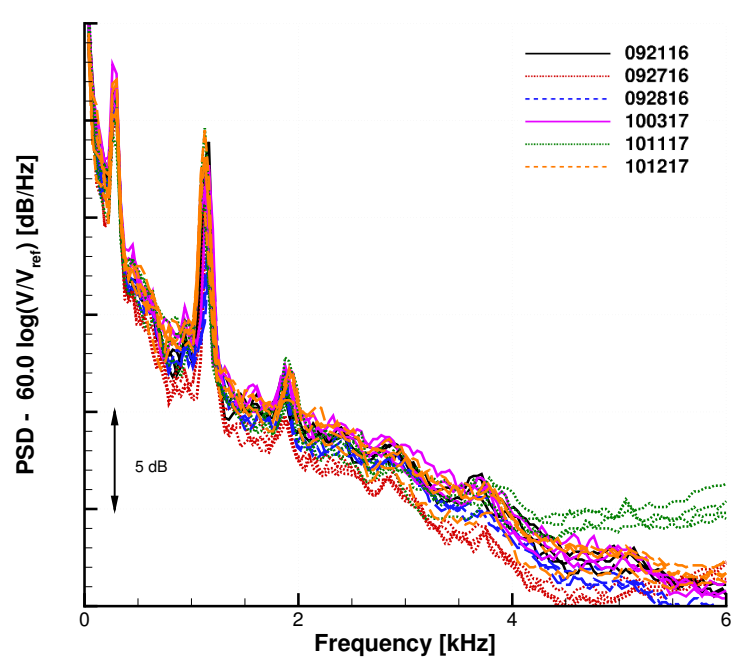

(a) 804 ACTE flaps at $25^{\circ}$

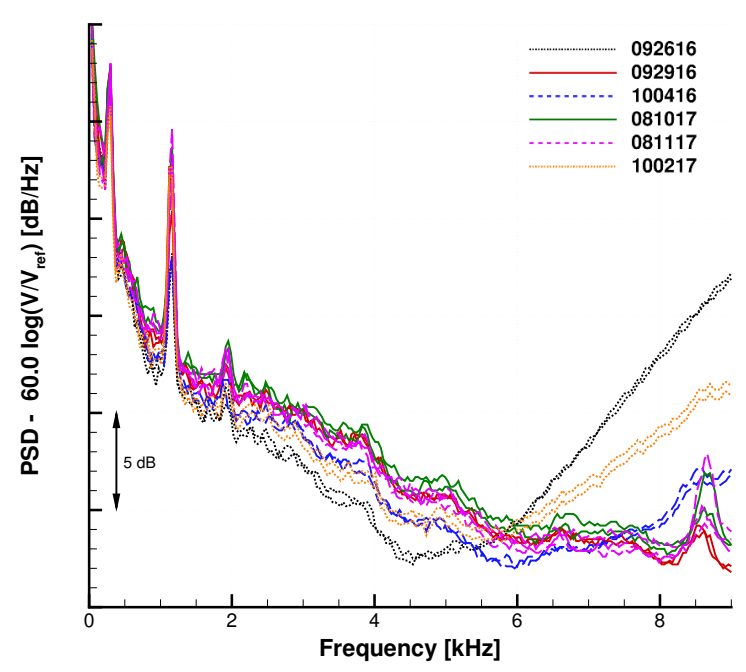

(b) 808 flaps at $20^{\circ}$

Fig. 33 Array average spectra for configurations with landing gear deployed and the aircraft between $\mathbf{- 3 0 0}$ to -200 ft $(-91$ to $-61 \mathrm{~m})$ in front of the array center.

limits, and obtain as many passes as possible on each day. Although obtaining such data is often prohibitive, one can have more confidence in the results when multiple data sets are involved.

\section{Acknowledgment}

This work was supported by the Flight Demonstrations and Capabilities (FDC) project under the Integrated Aviation Systems Program (IASP) of the NASA Aeronautics Research Mission Directorate.

\section{References}

[1] Humphreys, W. M., Lockard, D. P., Khorrami, M. R., Culliton, W., McSwain, R., Ravetta, P. A., and Johns, Z., "Development and Calibration of a Field-Deployable Microphone Phased Array for Propulsion and Airframe Noise Flyover Measurements," AIAA Paper 2016-2898, 2016.

[2] Humphreys, W. M., Lockard, D. P., Khorrami, M. R., Culliton, W., and McSwain, R., "Evaluation of Methods for In-Situ Calibration of Field-Deployable Microphone Phased Arrays," AIAA Paper 2017-4176, 2017.

[3] Mueller, T. J. (ed.), Aeroacoustic Measurements, Springer-Verlag, 2002.

[4] AVEC Time Domain Beamforming Software, Ver 2.70, AVEC, Inc., Blacksburg, VA, URL: http://www.avecengineering.com/products.html [cited Mar 17, 2018], 2018.

[5] Khorrami, M. R., Lockard, D. P., Humphreys, W. M., and Ravetta, P. A., "Flight-Test Evaluation of Airframe Noise Mitigation Technologies," To be presented at the 2018 AIAA Aeroacoustics Conference in Atlanta, GA, June 2018.

[6] True, H. C., "The Layered Weather Correction for Flyover Noise Testing,” AIAA Paper 1976-0895, 1976.

[7] McCollough, J., and True, H. C., "Effect of Temperature and Humidity on Aircraft Noise Propagation," FAA Report FAA-RD-75-100, 1975.

[8] Bass, H. E., Sutherland, L. C., and Zuckerwar, A. J., “Atmospheric Absorption of Sound: Update,” JASA, Vol. 88, No. 4, 1990, pp. 2019-2020.

[9] Bass, H. E., Sutherland, L. C., Zuckerwar, A. J., Blackstock, D. T., and Hester, D. M., "Atmospheric Absorption of Sound: Further Developments," JASA, Vol. 97, No. 1, 1995, pp. 680-683.

[10] Bass, H. E., Sutherland, L. C., Zuckerwar, A. J., Blackstock, D. T., and Hester, D. M., "Erratum: Atmospheric Absorption of Sound: Further Developments," JASA, Vol. 99, No. 2, 1998, p. 1259.

[11] Rickley, E. J., and Fleming, G. G., "Computing the Absorption of Sound by the Atmosphere and its Applicability to Aircraft Noise Certification,” US DOT FAA Report DTS-34-FA853-LR2, 1998. 
[12] Wallace, J. M., and Hobbs, P. V., Atmospheric Science: An Introductory Survey, Academic Press, 1977, Chap. 2, pp. $55-57$.

[13] Dougherty, R. P., “Advanced Time-domain Beamforming Techniques,” AIAA Paper 2004-2955, 2004.

[14] Sijtsma, P., and Stoker, R. W., "Determination of Absolute Contributions of Aircraft Noise Components using Fly-Over Array Measurements,” AIAA Paper 2004-2958, 2004.

[15] Takaishi, T., Ura, H., Nagai, K., Yokokawa, Y., Murayama, M., Ito, Y., Sakai, R., Shoji, H., and Yamamoto, K., "Flyover Array Measurements with JAXA Flying Test Bed 'Hisho',' AIAA Paper 2016-2710, 2016.

[16] Sijtsma, P., “CLEAN Based on Spatial Source Coherence,” AIAA Paper 2007-3436, 2007.

[17] Bohning, P., and Siller, H., "Study of a Deconvolution Method for Aircraft Flyover Measurements," AIAA Paper 2007-3474, 2007.

[18] Fares, E., Casalino, D., and Khorrami, M., "Evaluation of Airframe Noise Reduction Concepts via Simulations Using a Lattice Boltzmann Approach,” AIAA Paper 2015-2988, 2015.

[19] Khorrami, M. R., Humphreys, W. M., Lockard, D. P., and Ravetta, P. A., "An Assessment of Flap and Main Landing Gear Noise Abatement Concepts," AIAA Paper 2015-2978, 2015.

[20] Dougherty, R. P., “Turbulent Decorrelation of Aeroacoustic Phased Arrays: Lessons from Atmospheric Science and Astronomy," AIAA Paper 2003-3200, 2003. 